\title{
EFFECTS OF ADDING LIQUID LACTOSE OR MOLASSES TO PELLETED SWINE DIETS ON PELLET QUALITY AND PIG PERFORMANCE
}

\author{
A Thesis \\ By \\ KARA MICHELLE DUNMIRE
Submitted to the Office of Graduate and Professional Studies of Texas A\&M University in partial fulfillment of the requirements for the degree of

\section{MASTER OF SCIENCE}

Chair of Committee, Co-chair of Committee, Committee Members, Head of Department,
Chad B. Paulk

Tryon A. Wickersham

Jason Lee

G. Cliff Lamb

December 2017

Major Subject: Animal Science

Copyright 2017 Kara Michelle Dunmire 


\section{ABSTRACT}

Two experiments were completed to evaluate the effects of adding liquid lactose or molasses to pelleted swine diets on pellet quality and pig performance. A total of 194 nursery pigs were used in a 33-d experiment evaluating the effects of liquid lactose (SweetLac 63; Westway Feed Products, Tomball, TX) or cane molasses on nursery pig performance and pellet quality. Experimental diets were fed in pelleted form from d 0 to 21, and a common pelleted diet fed from d 21 to 33. Dietary treatments consisted of a control diet containing $19.1 \%$ total sugars from whey powder and whey permeate (control), and experimental diets with a percentage of whey permeate replaced by either 5 or $10 \%$ liquid lactose (SweetLac 63; Westway Feed Products, Houston, TX) (5\% LL and $10 \% \mathrm{LL}$, respectively) or $9.4 \%$ cane molasses $(9.4 \% \mathrm{M})$. Hot pellet temperature, production rate and percent fines decreased $(P<0.05)$ from the control to $9.4 \% \mathrm{M}$ treatments with 5\% LL and 10\% LL having intermediate effects. Pellet durability index (PDI) increased $(P<0.05)$ in 5\% LL, 10\% LL and 9.4\% M respectively. From d 0 to 7 , pigs fed the $9.4 \% \mathrm{M}$ treatment had the best G:F with $10 \%$ LL having the intermediate effect. Fecal consistency scores at d 7 were also firmer in pigs fed $9.4 \% \mathrm{M}$ with $10 \% \mathrm{LL}$ having the intermediate effect. There were improvements in ADFI from d 0 to 21 for pigs fed up to $10 \%$ LL in the diet. The addition of liquid lactose or molasses to nursery pig diets had an improvement on PDI pellet quality and decrease in percent fines.

In experiment 2, 289 finishing pigs were used in a 53-d experiment evaluating the effects of liquid lactose (SweetLac 63; Westway Feed Products, Houston, TX) on 
pellet quality, finishing pig performance and carcass characteristics. Experimental diets were fed in pelleted form from d 0 to 53 divided into 3 phases: $\mathrm{d} 0$ to $19, \mathrm{~d} 19$ to 36 , and d 36 to 53. Dietary treatments were a corn-soybean meal control diet with 0 (control), 2.5 (2.5\% LL), 5 (5\% LL), and 7.5\% (7.5\% LL) liquid lactose (as-is) added in the place of corn. Pellet durability index improved (linear, $P<0.01$ ) with increasing inclusion rates of liquid lactose. Throughout the 53-d experiment, there were no differences in ADG, ADFI or final BW. Pigs fed diets with increasing levels of liquid lactose tended to have improved (quadratic, $P=0.070$ ) $\mathrm{G}: \mathrm{F}$, with pigs fed the $2.5 \%$ liquid lactose diet having the best numerical G:F. Additionally, there were no differences among carcass characteristics. 


\section{ACKNOWLEDGEMENTS}

I would not have been able to do this without the help of many who have challenged and inspired me in ways I did not think were possible. To my committee, Dr. Paulk, Dr. Wickersham and Dr. Lee- thank you for agreeing to join me on this journey. To Dr. Paulk, thank you for providing me the opportunity to continue my education, providing support and challenging me. To Dr. Wickersham, thank you for adopting me as one of your graduate students and for inviting me to spend holidays with your family. To Dr. Leslie Frenzel, Del Rio would not have been as entertaining without you, your advice and knowledge were tremendous. To Mike Penn, I mostly drove you crazy out at the farm but I know that you loved it.

To my fellow graduate students, thank you for making Texas feel like home, I am better for knowing all of you. I look forward to seeing what life has in store for each of you and hope that one day our paths will cross again. The Swine Nutrition and Production (SNaP) Team - Sarah, Logan and Lily - thank you for all of the laughs and support in good and challenging times. You are all rock stars for helping my projects run smoothly. Jessica, Emily, and Amelia, thanks for fielding all of my questions, being listening ears, great roommates (pseudo-roommates) and friends.

I am thankful to have had many mentors thus far in my life and for each I am grateful. My achievements are a testament to you and the guidance and wisdom you have shared. To Coach Ben Williamson, thank you for encouraging me to undertake this graduate school journey and believing in me when I had doubts. To my friends that 
I consider family, while we are spread from coast to coast pursuing our dreams, please know that I think of you often and appreciate your love and support. Thank goodness for modern technology that we are able to remain so close when we live so far. To my family, they say you cannot pick your family but I would choose all of you, every time. I truly hit the family jackpot. Thank you for supporting all of my endeavors and cultivating my passion for agriculture. To my grandmothers and grandfather, I was only given you for a chapter of my life but your memory still lives in me every day. I hope I am making you proud. To Mom and Dad, my pillars, your love and support are unmatched. Dad, I have never met anyone that works harder than you, you are my inspiration to never give up and to figure it out when things get tough. You may say that "It's all about the money" but you do it all for your family and for others. Mom, you are so self-sacrificing for my happiness and the best cheerleader around. All that I am and hope to be, I owe to my mother. Above all, I thank God for giving me the courage to pursue my dreams, wherever they may lead.

"Seek his will in all you do, and he will direct your paths" Proverbs 3:6

Thank you will never be enough. 


\section{CONTRIBUTORS AND FUNDING SOURCES}

Contributors

This work was supervised by a thesis committee of Dr. Chad Paulk, chair, and Dr. Tryon Wickersham, co-chair, of the Department of Animal Science and Dr. Jason Lee of the Department of Poultry Science.

All work conducted for this thesis was completed by the student with advisement of Dr. Chad Paulk and Dr. Tryon Wickersham. Chapter II work was also advised by Dr. Leslie Frenzel of the Department of Animal Science.

Funding Sources

The following work was made possible in part by Westway Feed Products (Tomball, TX) and the American Feed Industry Association (AFIA; Arlington VA). 


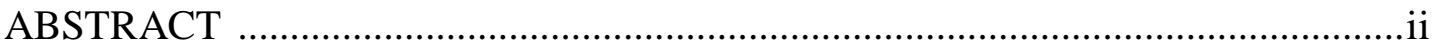

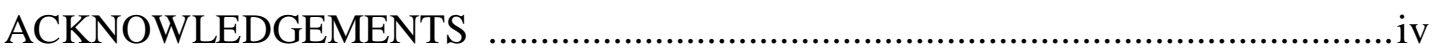

CONTRIBUTORS AND FUNDING SOURCES.................................................... vi

TABLE OF CONTENTS .............................................................................. vii

CHAPTER I INTRODUCTION AND REVIEW OF LITERATURE .......................1

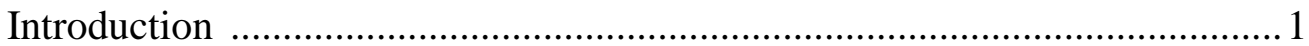

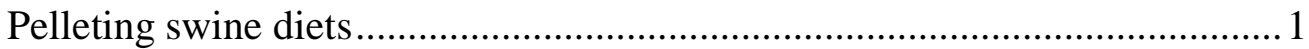

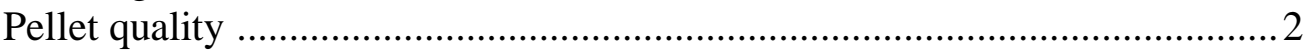

Effects of steam conditioning on pellet quality …………………….... 4

Effects of nutrients and ingredients on pellet quality ...........................6

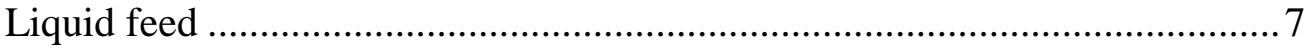

Sugar

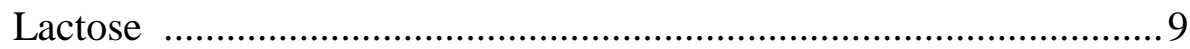

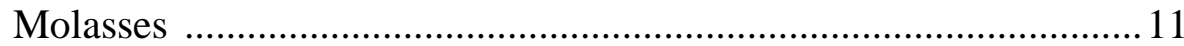

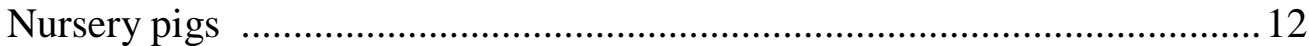

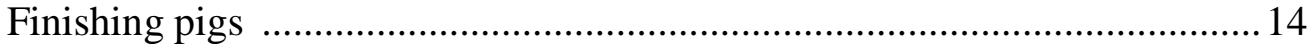

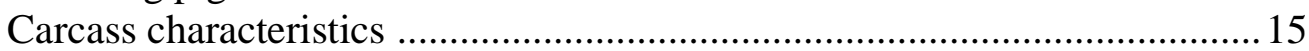

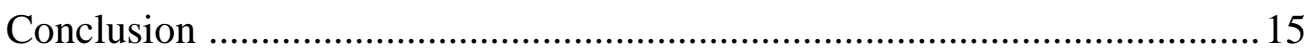

CHAPTER II EFFECTS OF ADDING LIQUID LACTOSE OR MOLASSES TO

PELLETED NURSERY PIG DIETS ON PELLET QUALITY AND PIG

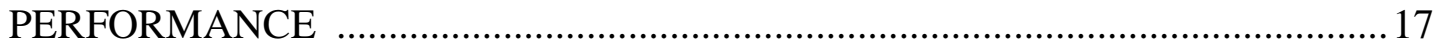

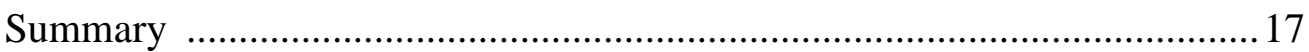

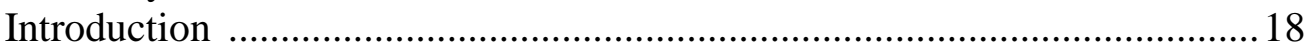

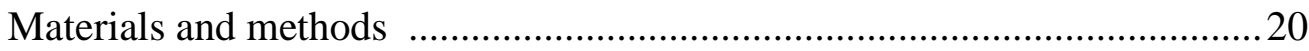

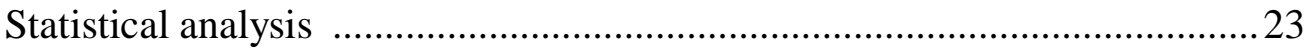

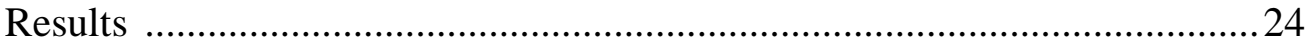

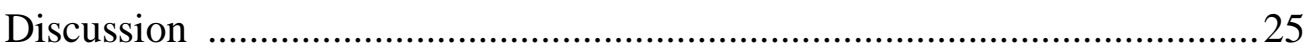

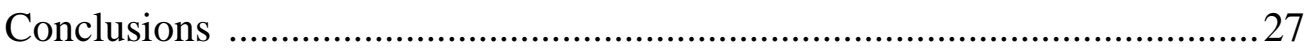


CHAPTER III EFFECTS OF ADDING LIQUID LACTOSE TO PELLETED

FINISHING PIG DIETS ON PELLET QUALITY, PIG PERFORMANCE AND

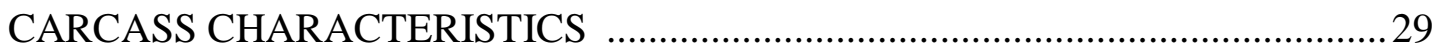

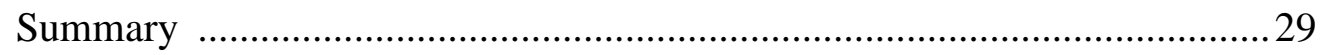

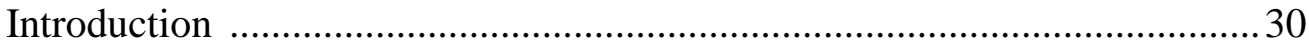

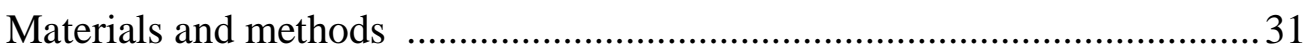

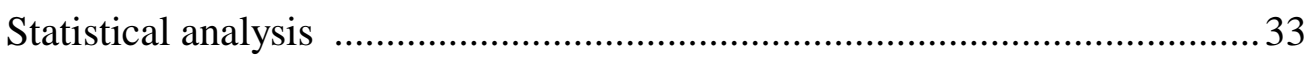

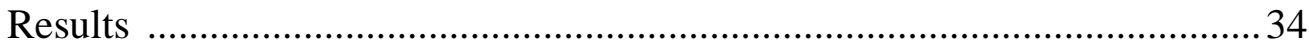

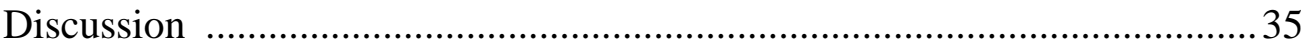

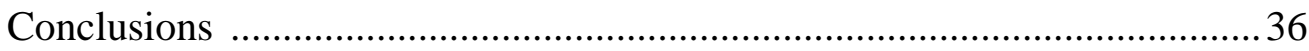

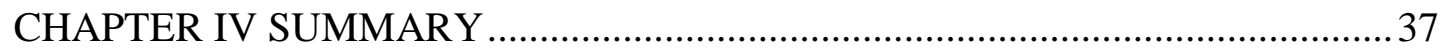

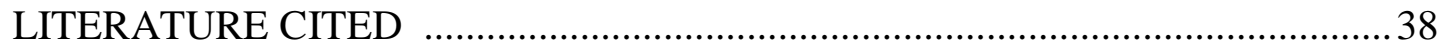

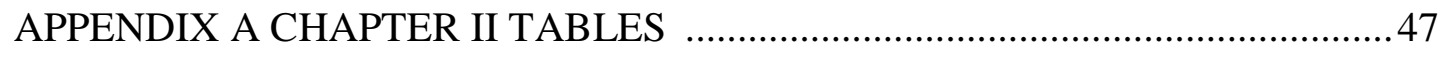

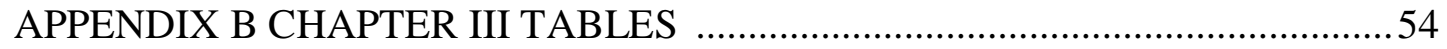




\section{CHAPTER I \\ INTRODUCTION AND REVIEW OF LITERATURE}

\section{Introduction}

Animal agriculture is a rapidly progressing and innovative industry. Efficiency, and the ability to produce more is a common thread throughout the industry. As the primary cost center for a producer, maximizing feed utilization is a major concern. Pellet processing parameters and feed formulation are key factors in optimizing economic returns in livestock species. While feed processing and pelleting are not novel ideas, it has only been recently where substantial achievements in these areas have occurred and been recognized. Sourcing alternative feed ingredients to either improve performance or reduce costs, ideally both, is a constant venture that often brings challenges. The following literature review explores the role of pellet quality in swine diets, explaining influential factors and how modifications to such factors impact pellet quality.

\section{Pelleting swine diets}

Swine diets are pelleted to improve feed handling characteristics through less waste, greater bulk density, and better feed distribution (Behnke, 1994). Waste is decreased with pelleting as fewer fines are generated, provided pellet quality is maintained. Pigs are more likely to receive an even distribution of nutrients when diets are pelleted, eliminating sorting and making for easier feeder management. An increase 
in bulk density maximizes storage capabilities. Flow ability through feeding systems is improved by eliminating bridging in storage bins, a common problem with mash diets. The high heat and temperature needed to form pellets is also responsible for the destruction of pathogens potentially found in grain. As previously mentioned, the overarching reason for pelleting pig diets is the growth performance advantage (Behnke, 1994). Management from both a producer and mill perspective determines the extent to which benefits are observed. However, adding an additional process before the feed leaves the mill requires time and money - two critical elements for producers. Additional processing, time and labor increases diet cost often deterring producers from pelleting. Therefore, swine diets, in most cases, are still fed in mash form.

\section{Pellet quality}

A pellet's ability to withstand packaging and transportation before consumption defines the pellet quality. Pellet quality is influenced by the formulation developed by the nutritionist and processing parameters. Nutritionists determine the formulation and particle size, whereas mill management determines conditioning, die specification, throughput, and pellet cooling (Behnke, 1994). Pelleting techniques vary from mill to mill. To maintain pellet quality as new ingredients are introduced a balance must established between formulations and pellet mill operation.

Pellet quality is measured as percent fines and pellet durability index (PDI), meant to simulate pellet breakage, due to product handling, from the mill to feed consumption. Immediately after the pellet is formed, it is exposed to many external 
forces, such as, cooling, bagging and transport. Pfost et al. (1962) established a standard tumble box method to determine PDI. A 500g sample of sifted pellets is added into a tumble box. The sample is then tumbled for 10 minutes at 50 revolutions per minute. Pellet durability index is defined as a percentage of whole pellets left after the sample has been tumbled (ASAE Standard S 269.4). To further demonstrate pellet breakage, "modified PDI" can be used. Modified PDI follows the same procedures as standard PDI, however pellet disruption is intensified by adding hex nuts or ball bearings to the tumble chamber (Fahrenholtz, 2012). In both the standard and modified PDI methods, fines can be calculated as the weight of the pellet present after agitation divided by the weight of the pellet before agitation. Typically, an increase in PDI means a decrease in percent fines as observed by Briggs et al. (1999) and Gilpin et al. (2002).

Through modifications of the standard and modified method established by Pfost et al. (1962), the Holmen pellet durability test has been established to provide a faster, higher intensity test. Holmen pellet testers by TekPro (NHP 100, 200, 300) disrupt pellets in a cone shaped chamber with pressurized air flow (www.tekpro.com/pellet_durability_tester, accessed Aug. 1 2017). When pellets are added a timer is set for $30,60,90$, or 120 seconds, a much smaller increment of time compared to the traditional method. Fines are captured by a filter during the process; therefore fines do not have to be sifted before the final weighing. NHP 200 and 300 are automatic and the NHP 300 model can be placed directly on the processing line. When considering the methods, the Holmen method is simpler and faster but more costly when 
compared to the traditional method established by Pfost et al. (1962). Still, more research is needed to truly compare the methods.

\section{Effects of steam conditioning on pellet quality}

The energy required to operate a pellet mill is minimized when the pellet mill is producing at maximum rate, which is process specific (Fahrenholz, 2012). Energy required to form pellets is largely influenced by steam, an additional cost center for manufacturers. Converting liquid water to vapor through heat causes evaporation from the liquid, thus requiring energy. With the addition of heat, pressure and temperature rise simultaneously as particles become excited. However, not all steam is created equal. Steam quality is defined as the percentage of steam-water mixture in the vapor phase (Reimer and Beggs, 1993). Saturated steam is completely vapor, whereas wet steam contains less than $100 \%$ vapor. More wet steam is required in order to steam condition the mash to the correct temperature. Temperature is also effected by steam quality where if the conditioning temperature is not obtained, the pellet die becomes clogged. It is at this point where pelleting becomes more trial and error. While steam conditioning is dependent on the mill personnel it is often overlooked during processing, although research reflects its importance.

Stoch et al. (1981) observed a $40^{\circ} \mathrm{C}$ increase in mash temperature when dry pelleting; however, a $5^{\circ} \mathrm{C}$ increase was observed when the mash was steam conditioned to $80^{\circ} \mathrm{C}$. Moisture serves as lubricant reducing pellet friction between the mash feed and the die (Stoch, et al., 1981). Amount of steam added is determined by the temperature 
and initial mash moisture to decrease mechanical friction from pellet formation. Gilpin et al. (2002) measured feed moisture, retention time, steam quality, and energy utilization from two conditioners. Both conditioners indicated they were significantly related to mash moisture (12 or 14\%), retention time (short or long), steam quality (70, 80,90 , or $100 \%$ ), and their interactions as influenced by energy consumption and steam flow to determine pellet quality. Additionally, these authors found that conditioning feed to $82.2^{\circ} \mathrm{C}$ with $100 \%$ quality steam required a lower flow rate $(\mathrm{kg} / \mathrm{h})$ than did the $70 \%$ quality steam for both conditioners. Excess moisture will negatively affects the pelleting process because of plugging and slippage between rolls and die; thereby, increasing energy consumption. Pellet quality at the lowest energy cost is dependent on mill management adjusting for mash moisture, retention time and steam quality (Gilpin, 2002). Greer and Fairchild (1999) observed that addition of moisture to the mixture can directly improve pellet quality and can be applied via several equipment options. "The Feed Pelleting Reference Guide" developed by researchers at Kansas State University and North Carolina State University, provides a general rule-of-thumb that for every $1 \%$ moisture added there is an approximate $12.5^{\circ} \mathrm{C}$ increase in temperature from steam. Where optimum conditioned mash moisture is $85^{\circ} \mathrm{C}$. In general, conditioned mash moisture should be from 16 to $17.5 \%$ having 4 to $5 \%$ of the moisture come from conditioning. The frictional heat is helpful in gelatinization of starch as well as destruction of harmful microbes (Reimer and Beggs, 1993). Researchers have found that steam conditioning provides a harder pellet that improves starch gelatinization, opening up the starch granule, increasing digestibility (Hancock and Behnke, 2000). While it 
could be thought of that steam pressure would have an effect on PDI, it must be balanced with costs and the requirements of the system (Fahrenholz, 2012). It is not uncommon for pellet mills to be operating beyond production capacity. Research has found that production rate will effect pellet durability and energy expenditure (Stark et al., 2009), as production rates increase pellet quality decreases.

\section{Effects of nutrients and ingredients on pellet quality}

Before pelleting, ingredient characteristics, their interactions and how they respond to the pelleting process must be addressed. Macro- and micronutrients react to pelleting in different ways. Irreversible reactions occur during pelleting to nutrients in the feed stuff. Proteins are volatile under pelleting conditions including temperature, shear, and moisture. Higher protein diets plasticize under heat (Bartikoski, 1962; MacBain, 1966) and form a harder pellet. Both Briggs (1999) and Calvalcanti et al. (2005b) found that protein increased PDI, Calvalcanti et al. 2005b, further found that soybean meal increased pellet quality. Calvacanti et al. (2005a) found that the interrelationship between protein and starch improved PDI of both were included at high levels in the diet. Structural carbohydrates increase pellet quality through improved compressibility; however production rate is often slower from compression. Starch, as previously mentioned, will gelatinize under heat, pressure, and shear. Gelatinization typically begins around 52 to $57^{\circ} \mathrm{C}$ under high moisture conditions (Stevens, 1987). The amylose and amylopectin of starch molecules become disrupted under the pelleting conditions. Branched amylopectin collapses and the helical amylose gelatinizes, holding 
the molecule together (Remsen and Clark, 1978). Higher fat diets help lubricate the pellet die; however, fat addition can have excessive die lubrication increasing production rate before pellet formation has occurred. Chemical stability of vitamins is of concern and typically addressed by chemical modification, spray drying, and particle size adjustment of the vitamin. The interrelationships of the macronutrients and micronutrients paired with pellet processing parameters effect the pellet durability and availability to the animal. Sourcing different ingredients and by-products to include in diets will change processing parameters.

\section{Liquid feed}

While nutrient type is influential to pellet quality, ingredient form (solid vs liquid) will affect pellet quality. Liquid feed ingredients can be used in swine diets, however, are most popular in cattle diets. Feedlots and dairies use liquid feeds as a way to reduce dustiness and ensure vitamin and mineral nutrient requirements are met. Liquid feed ingredients added to swine diets can be done in either mash or pelleted form. When adding liquids to both mash and pelleted diets, an even distribution of the liquid throughout the feed is critical which can be achieved by modifying mixing time. Mixing time is dependent on the type of mixer and amount of added moisture. Even ingredient distribution is important to ensure nutrient requirements are met (McCoy, 1992). Water is often added to achieve a specified moisture level before pelleting. This can depend on the initial dry matter of the feed. Liquids can also be applied by spraying the outside of the pellets before or after the pellet has been cooled (Fairfield et al., 2005). Molasses and 
fats are suggested to be sprayed into the mixture to allow even distribution throughout the mash. Otherwise, clumping of the mash and loss of pellet quality can occur. Liquids of high viscosity should be heated to decrease viscosity allowing better distribution and flow. Additionally, hydrophilic liquids should be added first before the addition of hydrophobic oils so that water can be absorbed for harder pellets. Viscous and sticky liquids can cause build up within the mixer, decreasing efficiency and increasing wear on equipment, therefore frequent cleaning could be a necessary additional cost (McCoy, 1992).

Pellet binders serve to provide a more durable pellet and reduce fines. Binding agents require water to be activated and improve adhesion and cohesion to feed particles. The most common pellet binders are inorganic clays and protein derived gums (NRC, 2012). Inorganic clays and lignosulphonates (byproducts from the paper industry) should to be included at 2 to $4 \%$ of the diet (AFFCO, 2010). Lignosulfonates are twice as effective as clays. While pellet binders increase pellet hardness, their influence on growth performance has not been determined (Hancock and Behnke, 2000).

Sugar

Pelleting sugar provides its own set of challenges. Pellet mill power requirements increase from the recrystallization of sugars as the mash and die come into contact (Thomas et al., 1993). Recrystallization after cooling of solubilized sugars causes binding between feed particulates and can act as a binder (Van den Berg, 1992). However, if sugars are not sufficiently solubilized due to moisture, added water, or 
steam, the benefits of pellet hardness and durability may not be observed. A majority of sugar is already solubilized in molasses, therefore there are positive effects on pellet hardness and durability with molasses (Thomas et al., 1993).

Maillard reaction risk increases with use of sugars in combination with amino acids and moisture. The glucose carbonyl combines with an amine group of amino acid forming glycosalamine. Especially when moisture is present, free aldehyde and amino groups may combine to form melanoides that darken the product (Motai, 1976) and affect color, odor and flavor. While this improves pellet durability, Maillard products may impair nutritional value (Van Barneveld, 1993; Hendriks et al., 1994). Mahan (1993), also suggests that Maillard Browning reactions potentially bind some of the lysine to lactose. Adrian (1967) found bound lysine is 5 to 15 times more likely to be involved compared to other amino acids because it contains a reactive free amino group and even more likely with free lysine. It is interesting to note however that Mavromichalis (2001) found that when lysine is used, a possible reversible reaction through deamination can be carried-out by intestinal microbes. If lysine is bound it can cause dramatically detrimental effects to pig growth performance, because lysine is the first limiting amino acid in growing swine.

\section{Lactose}

Most common sources of lactose include whey, whey permeate, deproteinized whey and crystalline lactose (Dritz et al., 1993; Owen et al., 1993b; Touchette et al., 1993; Nessmith et al., 1997a). As discussed later, lactose is beneficial in nursery diets. 
However, these are all milk byproducts and as such they are volatile, heat sensitive, and expensive. Therefore, spray dried whey is the preferred source. Lactose made of monosaccharides, glucose and galactose is also subject to the aforementioned Maillard browning reactions.

Based on the findings of the aforementioned researchers, phase 1 diets should contain from 15 to $25 \%$ lactose. Phase 2 diets are recommended to contain 10 to $15 \%$ lactose (Crow et al., 1995). Mahan et al. (2004) observed dietary lactose should be included at 25 to $30 \%, 15$ to $20 \%$, and 10 to $15 \%$ in phase 1,2 , and 3 diets respectively. Mahan observed during the initial 0 to $7 \mathrm{~d}$ postweaning period, there was a growth response only when lactose was added to corn gluten meal-soybean meal and dried whey diets suggesting that the limiting nutritional factor immediately post weaning was carbohydrate rather than amino acids. While these diets contained approximately $16 \%$ dietary lactose, there was still an observable growth response when lactose was added to the diet up to $32 \%$ total lactose. Additionally, from d 8 to 14 lactose addition did not enhance pig growth and in some cases resulted in reduced gain. From d 15 to $\mathrm{d} 21$, the addition of lactose did not improve growth performance. As age and weight gain increased, carbohydrate became the next limiting nutritional factor following amino acids. Mahan (2004) found that lactose replacing cornstarch resulted in linear increases in feed intakes and weight gains for the initial 14-d postweaning period. Throughout the entire 35-d trial period, there were improvements in growth except for in gain: feed. 


\section{Molasses}

Volatility in cost the cost of milk and milk byproducts has led to the investigation of alternate carbohydrate sources that will not negatively affect pig performance. Yang et al. (1997) found that growth performance was not affected when a chocolate product replaced some of the whey used in nursery products. Guo et al. (2015) used a candy coproduct of primarily sucrose to replace $45 \%$ of dietary lactose, which at the time was $45 \%$ of the price of whey powder and $68 \%$ of the price of whey permeate. Another alternative to consider is sugarcane molasses. As defined by the USDA, sugarcane molasses is as a clean liquid product by the evaporation of the juice of sugarcane and the removal of commercially crystalizable sugar (USDA, 1969). Grading of sugarcane molasses requires a minimum brix, total sugars, ash, total sulfites and color score. Sugarcane molasses contains $47.5 \%$ sucrose as a percent of carbohydrate components (NRC, 2012).

Diets high in sucrose (Becker et al., 1954a, b) or molasses (Ly, 1996) have been known to cause scours. Molasses can induce scours at levels greater than $20 \%$ inclusion (Myer and Brendemuhl, 2000). However, scours can be mitigated by dilution of molasses done by blending with a fibrous residue of sugarcane after processing. In weaned pigs, the limited presence of sucrase in the small intestines can be the cause of scours (Becker et al., 1954a; Aherne et al., 1969) as sucrose_and are found at high concentrations molasses. The molasses-scours relationship varies across projects, and may be driven by molasses quality. Levels up to $20 \%$ molasses may have been found 
acceptable for pigs weighing 10 to $50 \mathrm{~kg}$, and over $50 \mathrm{~kg}$ molasses can be included up to 40\% (Combs and Wallace, 1973; Loeza et al.,1997)

Nursery pigs

Numerous studies have been conducted to determine mash verses pelleted diets on nursery pig performance. In two nursery experiments, Stark (1994) performed experiments to determine pellet quality with a mash, pelleted with increased fines and a pelleted diet. In the first experiment, pellets had a 97\% PDI and 94\% PDI in the second experiment. Pigs fed the pelleted diet had a 10\% improvement in ADG and 14\% improvement in G:F. Nemechek et al. (2015) conducted 2 nursery experiments with pelleted diets that had 33\% fines and diets with 3\% fines. Pigs fed diet with 3\% fines had improved G:F compared diets with 33\% fines or meal diet. In the second experiment, Nemechek et al. (2015) had diets 37\% fines and 5\% fines. Those researchers found that $37 \%$ or $5 \%$ fines had increased ADG compared to pigs fed the meal diet. Similar to experiment 1, pigs fed pellets with only $5 \%$ fines had improved G:F compared all other diets (Nemechek, 2015).

Arguably, the most critical nutritional period of a pig is the first few weeks post weaning. The transition from liquid to solid feed as well as milk based to plant based diets remains an area of extensive research. This is also the time feed is more expensive for producers. Klobasa et al. (1987) reported milk composition at the time of weaning with a decrease in total protein and whey protein contents. After a $6 \mathrm{~h}$ colostrumlactation period, fat and lactose content increased with nearly unchanged levels of total 
solids. It is the decrease in protein constituent that indicates a transition from colostrum to mature milk (Klobasa et al., 1987). Foundational work with carbohydrate digestive enzymes has helped to distinguish simple versus complex carbohydrates and utilization by nursery pigs. The primary enzyme present the first few months of age is lactase (Heilsikov, 1951; Dalhiqvist, 1961) which is found in abundance in the small intestine of nursery pigs, up to the week after weaning. Lactase is more readily available on the villi of the small intestine than sucrose-isomaltase. When lactase production and activity decrease at weaning, sucrase availability increases (Nordstrom and Dahlqvist, 1973; Kelly, 1991b; Guo et al., 2015). As the intestine develops, enzyme presence changes and sucrose-isomaltase becomes more prevalent. Weaning initiates a decrease in activity for carbohydrases due to stressors. The onset of sucrase-isomaltase activity is the result of induction effects of sucrose becoming more prevalent the diet. Sucraseisomaltase level, mRNA, and sodium-glucose linked transporter mRNA increase when sucrose is added to the diets (Manners and Stevens, 1972; Flores, et al., 1988; Yasutake et al., 1995). This transition occurs by 4 weeks of age.

Lactobacilli implantation in large intestines increases with presence of lactose. These microbes result in increased volatile fatty acid production in the large intestine. Fermentative action of lactobacilli increases acidity and inhibits harmful microbial proliferation such as Escherichia coli and, therefore aid, in growth performance by decreasing scours. Sucrose can also be fermented by lactobacilli; however, not as efficiently as lactose. 


\section{Finishing pigs}

Moser et al., (1980) observed increased feed intake and poorer feed conversion in pigs fed no lactose and no effect on ADG. They attributed poor feed conversion to a greater feed intake by pigs fed lactose. Adaptation may have resulted from dietary lactose causing an increase in lactase activity, as reported by Bolin et al., (1969).

Numerous studies have been done testing mash diets and pelleted diets of finishing pigs. Stark et al., (1994) conducted a finishing experiment to determine pellet quality effects on finishing pig growth performance. Compared to those fed the meal diet, pigs fed the pelleted diet had improved ADG of $3 \%$ and feed efficiency of $5 \%$. Feed efficiency improvements for pigs fed pelleted diets were lost as the amount of fines increased. Wondra et al. (1995) fed mash and pelleted diets and had a 4 to $6 \%$ improvement in ADG in pigs fed pelleted diets. De Jong et al. (2016) observed pigs fed meal had the greatest ADFI, whereas pigs fed pellets had the lowest. Additionally, pigs fed pelleted diets throughout had the greatest G:F, whereas pigs fed meal were least efficient. Feed efficiency of 7 and 6\% as observed Wondra et al. (1995) and De Jong et al. (2013), respectively, comparing pigs fed mash and pelleted diets. Feeding pelleted diets increased ADG and improved G:F, but diet form did not influence HCW or carcass yield (Nemechek et al., 2015). It is understood that an average improvement of $6 \%$ ADG and 6 to 7\% G:F improvement will be observed when pelleting diets (Richart, 2000). 


\section{Carcass characteristic}

Many researchers have found no differences in carcass characteristics when compared to pigs fed meal diets (Paulk and Hancock 2015; Nemechek et al., 2016; De Jong et al., 2016). However, Potter et al. (2010) found that pigs fed pelleted diets had better gain efficiency, heavier market weight, and heavier carcass weights when compared to pigs fed meal diets. Stomach ulceration is a problem with pelleting diets but is also linked to genetic line, particle size, and environmental stressors (Richert 2000).

\section{Conclusion}

Feed is the largest economic expenditure for swine producers and making such feed as efficient and as low cost as possible is a goal for every producer. The overarching advantage of pelleting swine diets is the improvements in growth performance. However, this comes with additional cost. Measuring pellet quality is important to ensure feed efficiency advantages are achieved. New ingredients incorporated into mash diets will affect processing parameters of pelleting. Additionally, ingredient characteristics such as moisture and sugar content, will affect pellet quality, as well as their interrelationships with other nutrients. Pelleting diets has been proven to improve growth performance of nursery pigs and finishing pigs, as long as pellet quality is maintained. However, carcass characteristics are unchanged from mash to pelleted diets. Future research should be done comparing traditional tumble box method and Tekpro NHP pellet analyzers as measurements of pellet quality to determine 
efficiency and economics. More information on the incorporation of liquid ingredients into pelleted diets should be addressed, which could provide options for byproducts and other ingredients. 


\section{CHAPTER II}

\section{EFFECTS OF ADDING LIQUID LACTOSE OR MOLASSES TO PELLETED NURSERY PIG DIETS ON PELLET QUALITY AND PIG PERFORMANCE}

\section{Summary}

A total of 194 nursery pigs (DNA Genetics, Line $241 \times 600$, Columbus, NE; initially $6.7 \pm 0.4 \mathrm{~kg}$ at $27 \mathrm{~d}$ of age) were used in a $33 \mathrm{~d}$ experiment evaluating the effects of liquid lactose (SweetLac 63; Westway Feed Products, Tomball, TX) or cane molasses on nursery pig performance and pellet quality. At weaning, pigs were allotted to pens by initial BW and pens were randomly assigned to 1 of 4 dietary treatments within location block in the barn. There were 8 pens per treatment with 4 to 7 pigs per pen. The number of barrows and gilts per pen balanced across treatment. Experimental diets were fed from d 0 to 21 , and a common diet fed from d 21 to 33 . Dietary treatments consisted of a pelleted control diet containing $19.1 \%$ total sugars from whey powder and whey permeate (control), and a percentage of whey permeate was replaced by either 5 or $10 \%$ liquid lactose (SweetLac 63; Westway Feed Products, Houston, TX; $5 \%$ LL and $10 \%$ LL, respectively) or $9.4 \%$ cane molasses $(9.4 \% \mathrm{M})$ for dietary treatments. All diets were balanced for standard ileal digestible (SID) lysine and total sugars. Hot pellet temperature decreased $(P<0.05)$ when $10 \%$ LL was added to the diet when compared to the control, with 5\% LL and 9.4\% M treatments having an intermediate effect. Production rate decreased $(P<0.05)$ when $10 \%$ LL was added to the diet compared to the control, with 5\% LL and 9.4\% M treatments having an 
intermediate effect. Holmen $60 \mathrm{~s}$, increased $(P<0.05)$ with 5\% LL, 10\% LL and 9.4\% $\mathrm{M}$ added to the diet with no differences among the $10 \% \mathrm{LL}$ and $9.4 \% \mathrm{M}$ treatments. For Holmen 120 s, PDI increased $(P<0.05) 5 \%$ LL, 10\% LL and 9.4\% M, respectively. From d 0 to 21, there were no differences in pig ADG and G:F between treatments. There was an increase $(\mathrm{P}<0.05)$ in ADFI of pigs fed up to $10 \% \mathrm{LL}$ in the diet. From $\mathrm{d} 0$ to $33, \mathrm{ADFI}$ increased $(\mathrm{P}<0.05)$ in pigs fed $10 \%$ LL compared to those fed the control diet, with pigs fed the 5\% LL and 9.4\% $\mathrm{M}$ diets having intermediate ADFI. Additionally, fecal constancy scores at d 7 were firmer $(P<0.05)$ in pigs fed $9.4 \% \mathrm{M}$ with the $10 \%$ LL treatment having an intermediate effect. In summary, the addition of liquid lactose or molasses to nursery pig diets had an improvement in PDI pellet quality and decrease in percent fines without negatively impacting pig performance.

\section{Introduction}

Getting nursery pigs started on feed and off to a good start is one key to success for swine producers. Milk and animal-based products are included in early nursery pig diets to help weaned pigs transition from a milk-based liquid diet to a plant-based solid diet. Dried whey powder and dried whey permeate (73\% and $85 \%$ lactose, respectively) are milk based products commonly used in nursery pig diets. Previous research has demonstrated that increasing the levels of lactose in nursery pig diets using dried whey resulted in an improvement in pig performance (Mahan et al., 2004). This can be explained by the high level of lactase activity in a newly weaned pig which leads to lactose being more digestible than starch (Tokach et al., 1994). Although these specialty 
ingredients result in improvements in pig performance, they add significant cost to nursery pig diets. Previous research has demonstrated that a portion of whey may be replaced by non-lactose carbohydrate sources. These alternative carbohydrates include dextrose, sucrose, or by-products of candy manufacturers (Stephas and Miller, 1998). One possible source of sucrose is sugar cane molasses. Sugar cane molasses is a byproduct of the cane sugar refining. It contains approximately $47.5 \%$ sucrose. A possible alternate lactose source is liquid lactose (SweetLac 63; Westway Feed Products, Tomball, TX), a byproduct of the cheese making process. SweetLac 63 is a condensed liquid feed ingredient that contains high concentrations of lactose (36\%) with additional simple sugars glucose $(5.2 \%)$, maltose $(3.5 \%)$, and fructose and sucrose $(<0.1 \%)$.

Pelleting swine diets has been shown to have benefits for both the swine producer and the feed manufacture. Based on the average of data summarized by Paulk (2011), pelleting diets for growing-finishing pigs resulted in improvements in rate and efficiency of gain. However, the benefits in pig performance due to pelleting can be lost if pellet quality is not maintained. Stark et al (1994) reported decrease in feed efficiency of nursery pigs when fed pelleted diets with up to $25 \%$ fines. Schell and van Heugten (1998) reported a linear decrease in G:F in growing pigs as pelleting fines increased from 2.5 to $40 \%$. Therefore, improving pellet quality without reducing pellet mill throughput would benefit profit of feed mill manufactures and swine producers. Improved pellet quality can be observed through the addition of a steam conditioner. Skoch et al. (1981) found that increased steam conditioning led to a decrease in 
mechanical friction during pelleting due to lower hot pellet temperature rise across the pellet die and, therefore, improvement in pellet durability.

Alternative sources of lactose or non-lactose carbohydrates were evaluated for inclusion in nursery pig diets. It is hypothesized that liquid lactose (SweetLac 63; Westway Feed Products, Tomball, TX) or sugar cane molasses can be included in diets to improved pellet quality, leading to improvements in nursery pig performance. The objective of this experiment is to evaluate the use of liquid lactose or sugar cane molasses in nursery pig diets on pellet quality and growth performance.

\section{Materials and methods}

Texas A\&M University Institutional Animal Care and Use Committee approved the protocol used in this experiment. The study was conducted at Texas A\&M University, O.D. Butler Animal Science Teaching, Research and Extension Center (College Station, TX).

A total of 194 nursery pigs (Line $241 \times 600$; DNA Genetics, Columbus, NE;

initially $6.7 \pm 0.4 \mathrm{~kg}$ ) from 2 consecutive groups were used in a $33 \mathrm{~d}$ trial with treatments replicated equally in both groups. Pigs were weaned at $27 \mathrm{~d}$, moved to the nursery, and started on dietary treatments. Pigs were housed in 16 pens per group $(1.5 \times 1.5 \mathrm{~m}$ metal slatted pens). Pens were equipped with nipple waterers and 4 to 5 hole stainless steel feeders for ad libitum access to water and feed. At weaning, pigs were assigned to pens balanced by BW with 4 to 7 pigs per pen. Group 1 pens contained 7 total pigs with 4 gilts and 3 barrows or 4 barrows and 3 gilts. Group 2 pens contained 5 or 6 total pigs 
with 3 or 4 gilts, respectively, and 2 barrows. Pens of pigs were allotted to 1 of 4 dietary treatments balanced by initial BW, number of barrow and gilts per pen, and within group. Pens of pigs were also blocked by location within group. Overall, there were 8 pens per treatment. Dietary treatments consisted of a control diet containing $19.1 \%$ total sugars from whey powder and whey permeate, and the control diet with a percentage of whey permeate replaced by either 5 or $10 \%$ liquid lactose (SweetLac 63; Westway Feed Products, Houston, TX) or 9.4\% cane molasses. All diets were balanced for SID Lys and total sugars and fed in pelleted form. Diets were formulated with consideration of increased moisture content provided by liquid lactose and molasses. Concentration of diet components were initially decreased to allow for moisture loss during the pelleting process. After pelleting, expected levels of dietary components were achieved. Dietary treatments were split into 2 separate phases. Phase 1 was fed from day 0 to 7 and phase 2 from day 7 to 21 . Phase 3 was a common pelleted diet fed across all pens from day 21 to 33 .

Phase 1 and 2 were mixed and pelleted at the Texas A\&M University Poultry Science Teaching, Research, and Extension Center using a CPM Pellet Mill (Master Model HD, Series 2000). In order, to pellet the 10\% LL and 9.4\% M diets the process was done without the addition of steam. To remain consistent, no steam was added while pelleting any diets. Pellet mill throughput and hot pellet temperature were measured during pelleting. Four consecutive 60 second collections of pellets were weighed to measure production rate. Hot pellet temperature was measured at the center of the sample after all pellets were collected. A representative sample was used to determine 
percent fines and pellet durability index (PDI). Percent fines were established by the difference of the weight of the sifted pellet and the weight of the sifted pellet after tumbling divided by the weight of the sifted pellets. A Seedburo Pellet Durability Tester with $4,0.3 \times 0.14 \times 0.3 \mathrm{~m}$ tumble chambers was used to determine PDI. Pellet subsamples of $0.23 \mathrm{~kg}$ were collected from pellets fed into a one-gallon bag per treatment per phase. Each diet and phase had four 500-g samples sifted with a number-6 screen $(3.35 \mathrm{~mm})$ sifter. The sifted samples were tumbled for 10 minutes, simulating breakage from the time pellets are expelled until consumed by the animal. After tumble, pellets were re-sifted using the number-6 screen $(3.35 \mathrm{~mm})$ sifter and weighed. As an additional measurement of pellet durability, the Holmen pellet durability test was performed at Kansas State University using the Holmen NHP100 (Tekpro Limited, Norflok, United Kingdom; Table 4). Samples of 100-g were weighed and sifted then tested at 60 and 120 seconds under a pressurized air flow to simulate breakage from mill to consumption. With all methods, pellet durability index was calculated as weight of pellets after tumbling/weight of pellets before tumbling $\times 100$ (ASAE S269.4; ASAE, 1991).

Pig weights and feed disappearance were measured on d 0, 7, 21, and 33 for calculation of ADG, ADFI, and G:F. Fecal samples were collected on d 7 and 14 to visually examine fecal consistency and to determine DM of fecal samples. Samples were collected using rectal massage from 4 pigs per pen. Then, 5 individuals, blinded to treatments, scored samples based on a scale provided by Smiricky (2002). The scale is as follows; $1=$ hard, dry pellet; 2 = firm, formed stool; 3 = soft, moist stool that retains 
shape; $4=$ soft, moist stool that assumes shape of container, and $5=$ water liquid that can be poured. An average of individual scores was taken by sample and by pen. Fecal samples were then used for partial and laboratory DM. Entire sample was then weighed and dried in a forced-air drying oven at $50^{\circ} \mathrm{C}$ for 24 -h. Samples were allowed to air equilibrate for 24-h and weighed to complete partial DM. Laboratory DM was obtained by grinding samples in a Hamilton Beach coffee grinder. A 1-g subsample from the original sample was then weighed and dried at $105 \mathrm{C}$ for $24-\mathrm{h}$. DM samples were air equilibrated in a desiccator for 0.25 -h and weighed to determine final percent DM.

Statistical analysis

Pellet data was analyzed as a randomize complete block design using PROC MIXED in SAS (SAS Institute, Inc., Cary, NC) with batch of feed as the experimental unit. Dietary treatments were used as a fixed effect. Phase was used as a blocking factor and considered a random effect. Treatment means were separated using the PDIFFS option from the LSMEANS statement of SAS. Results from experiment were considered significant at $P<0.05$ and a tendency between $P>0.05$ and $P \leq 0.10$.

Growth data was analyzed as a generalized random complete block design using PROC MIXED in SAS (SAS Institute, Inc., Cary, NC) with pen as experimental unit. Dietary treatments were used as a fixed effect. Pen location within group was used as a blocking factor and considered a random effect. Treatment means were separated using the PDIFFS option from the LSMEANS statement of SAS. Results from experiment were considered significant at $P<0.05$ and a tendency between $P>0.05$ and $P \leq 0.10$. 
Results

Hot pellet temperature and production rate decreased $(P<0.05)$ when $10 \% \mathrm{LL}$ was added to the diet compared to the control, with 5\% LL and 9.4\% M treatments being intermediate (Table A4). Percent fines decreased $(P<0.05)$ from the control to $9.4 \% \mathrm{M}$, with 5\% LL and 10\% LL being intermediate. Standard PDI increased $(P<0.05)$ with 9.4\% M compared to the control, with 5\% LL and 10\% LL being intermediate. For the Holmen 60 s, PDI increased $(P<0.05)$ with 5\% LL, 10\% LL and 9.4\% M added to the diet with no differences among the $10 \% \mathrm{LL}$ and $9.4 \% \mathrm{M}$ treatments. For Holmen $120 \mathrm{~s}$, PDI were least $(P<0.05)$ for control followed by 5\% LL, 10\% LL and 9.4\% M.

From d 0 to 7, there were no significant treatment effects on ADG or ADFI. Pigs fed the control and 5\% LL had decreased $(P<0.05) \mathrm{G}: F$ compared to pigs fed $10 \% \mathrm{LL}$ and 9.4\% M (Table A5). From d 7 to 21, there were no differences in ADG or G:F. Pigs fed $10 \%$ LL had increased $(P<0.05)$ ADFI compared to the control with the $5 \%$ LL and 9.4\% $\mathrm{M}$ treatments having an intermediate effect. From d 21 to 33, pigs fed the $9.4 \% \mathrm{M}$ treatment had decreased $(P<0.05)$ ADG compared to those fed control and the $10 \% \mathrm{LL}$ diets.

From d 0 to 21, there were no treatment effects on ADG or G:F. In pigs fed the control diet, ADFI decreased $(P<0.05)$ compared to those fed $10 \%$ LL with $5 \%$ LL and 9.4\% $\mathrm{M}$ being intermediate (Table A5). From d 0 to 33, ADFI increased $(P<0.05) 10 \%$ LL inclusion when compared to all diets. Overall, there were no treatment effects on ADG or G:F. 
Fecal consistency on $\mathrm{d} 7$ was improved $(P<0.05)$ in the $9.4 \% \mathrm{M}$ diets compared to the control and 5\% LL diets (Table A6). There were no treatment effects in fecal consistency score on d 14 .

Discussion

Moisture serves as lubricant reducing the pelleting friction between the feed and the die (Stoch, et al., 1981). Inclusion of sugar increases the resistance at the feed-die interface (Thomas et al., 1998). In order to pellet the current experimental diets with $10 \% \mathrm{LL}$ and $9.4 \% \mathrm{M}$, the process was done without the addition of steam due to mill limitations of die plugging. Therefore, no steam was added while pelleting any diets to remain consistent. However, liquid ingredients add lubrication to the die keeping hot pellet temperature from increasing.

Pellet quality, as measured by percent fines and PDI, was improved when liquid lactose or molasses were added to the diet compared to the control. Recent research indicates the pellet quality benefits of steam conditioning up to $17 \%$ (Feed Pellet Reference Guide). In the experiment herein, the addition of moisture from adding 5\% LL, $10 \% \mathrm{LL}$, and $9.4 \% \mathrm{M}$ treatments to the mixer were $1.59 \%, 3.17 \%$, and $2.43 \%$, respectively. In addition to added moisture, binding properties of sugars might occur via recrystallization of sugars or the formation of a glass after cooling (Thomas et al. 1998). Prolonged exposure to heat in the pellet die has been suggested to increase "cook" and pellet durability (Fahrenholz, 2012). The risk of Maillard browning reactions will increase with use of sugars. Especially when moisture is present. Free aldehyde and 
amino groups may combine to form melanoides that darken the product (Motai, 1976). While this improves pellet durability, Maillard products may impair nutritional value (Van Barneveld, 1993; Hendriks et al., 1994). Mahan 1993 also suggests that Maillard Browning reactions potentially bind some of the lysine to lactose.

Pelleting swine diets has been proven to improve growth performance and decrease feed wastage (Stark, 1994). Stark (1994) observed that nursery pigs fed pelleted diets had a $10 \%$ and $14 \%$ improvement in ADG and G:F, respectively, compared to pigs fed mash diets. Nemechek et al. (2015) observed nursery pigs fed mash diets tended to have decreased ADG and G:F compared with pigs fed pellets, with an intermediate response in $\mathrm{ADG}$ and $\mathrm{G}: \mathrm{F}$ in those fed poor-quality pellets. However the benefits of pelleting come with an increase in diet cost. Although pellet quality was improved in the current experiment, it did not result in improved growth performance.

Lactose is essential in post weaning pig diets for up to 3 weeks after weaning (Fahey, 2000). Nessmith et al., (1997) found that the lactose fraction of dried whey can be replaced by crystalline lactose and deproteinized whey in nursery pig diets; however, these replacements must be of equal quality to the dried whey. Touchette et al., (1995) also observed that crystalline lactose was an acceptable alternative to dried whey in nursery pig diets. Most common sources of lactose include whey, whey permeate, deproteinized whey, and crystalline lactose (Dritz et al., 1993; Owen et al., 1993b; Touchette et al., 1995; Nessmith et al., 1997a). In the experiment conducted herein, liquid lactose was evaluated to be a replacement to dried whey and whey permeate. The control diets were formulated to have 18.7 and $10.1 \%$ lactose or total sugars for phase 1 
and 2 diets, respectively. In our experiment, 12.8 and $25.1 \%$ of the total sugar in phase 1 diets and 22.8 and $44.5 \%$ of the total sugar in phase 2 diets were replaced using $5 \%$ LL and $10 \% \mathrm{LL}$, respectively. Because LL is a majority lactose with a minority of other sugars, this resulted in the final 5\% LL and 10\% LL diets having 97.3\% lactose with 2. $7 \%$ other sugars and $95.2 \%$ lactose with $4.8 \%$ other sugars for phase 1 and $96.0 \%$ lactose with $4.0 \%$ other sugars and $91.1 \%$ lactose with $8.9 \%$ other sugars for phase 2 , respectively. In this experiment it was demonstrated that up to $10 \%$ LL could be added to the diet without negatively influencing growth performance.

Alternate sugar sources have been proven to partially replace up to $45 \%$ of dietary lactose in nursery pig diets using candy co-products (Guo et al. 2015). In previous experiments, candy co-products increased intakes due to added sweetness from sucrose compared to lactose. In the experiment herein, sugars for phase 1 diets were $24.6 \%$ other sugars and $75.4 \%$ lactose whereas phase 2 diet sugars were $44.05 \%$ other sugars and 55.45\% lactose. Mavromichalis et al. (2001) found that diets with molasses which is composed of sucrose can effectively replace the lactose portion of nursery pig diets. When pigs were fed the $9.4 \% \mathrm{M}$ treatment growth performance was intermediate compared to all other diets with firmer fecal consistency at d 0 to 7 . When pigs were fed the common diet after being fed the $9.4 \% \mathrm{M}$ treatment, ADG decreased.

\section{Conclusions}

Hot pellet temperature and production rate decreased when $10 \%$ LL was added to the diet, with 5\% LL and 9.4\% M treatments having intermediate effects. The addition 
molasses to nursery pig diets had an improvement on PDI pellet quality and decrease in percent fines without negatively impacting pig performance with liquid lactose at 5\% LL and $10 \% \mathrm{LL}$, respectively having intermediate effects. However, more research is needed to troubleshoot pelleting challenges.

Growth performance and fecal consistency of nursery pigs was not negatively affected with inclusion of liquid lactose or molasses in the diet. However, the current study would suggest that increasing liquid lactose to up to $10 \%$ of the diet would increase nursery pig feed intake from $\mathrm{d} 0$ to 21 post weaning. The data suggests that trends and differences in ADFI may contribute to ADG improvements. Although, pigs fed up to $10 \%$ liquid lactose had numerically the heaviest $\mathrm{BW}$, these differences were not significant. Therefore, ingredient and diet cost should be considered when selecting the appropriate sugar combination in the diet formula. 


\section{CHAPTER III}

\section{EFFECTS OF ADDING LIQUID LACTOSE TO PELLETED FINISHING PIG DIETS ON PELLET QUALITY, PIG PERFORMANCE, AND CARCASS CHARACTERISTICS}

Summary

A total of 289 finishing pigs (DNA $241 \times 600$; initially $53.5 \pm 0.5 \mathrm{~kg} \mathrm{BW}$ ) were used in a $53 \mathrm{~d}$ experiment evaluating the effects of liquid lactose (SweetLac 63; Westway Feed Products, Houston, TX) on finishing pig performance and pellet quality. Pigs were allotted to pens by BW and pens were randomly assigned to 1 of 4 dietary treatments within location block and group. There were 6 pens per treatment with 8 to 14 pigs per pen, with number of pigs per pen and gender balanced across treatment. Dietary treatments were a corn-soybean meal control diet with $0,2.5,5$, and $7.5 \%$ liquid lactose (as-is) added in the place of corn. All diets were balanced for standardized ileal digestible (SID) lysine. Diets were fed in pelleted form and pellet quality was assessed based on pellet durability index (PDI) and percentage fines. Pellet durability index improved (linear, $P<0.01$ ) with increasing inclusion level of liquid lactose. There were no differences in ADG, ADFI and final BW. Pigs fed diets with increasing levels of liquid lactose tended to have improved (quadratic, $P=0.07$ ) $\mathrm{G}: \mathrm{F}$, with pigs fed the $2.5 \%$ liquid lactose diet having the greatest G:F. There were no differences in carcass characteristics. In summary, diets with added liquid lactose had an improved pellet quality with no differences in growth performance or carcass characteristics. 


\section{Introduction}

Pelleting swine diets has demonstrated benefits for both the swine producer and the feed manufacture. Based on the average of data summarized by Paulk (2011), pelleting diets for growing-finishing pigs resulted in improvements in rate and efficiency

of gain. However, these benefits in pig performance due to pelleting can be diminished if pellet quality is not maintained. Schell and van Heugten (1998) reported a linear decrease in G:F in growing pigs as pelleting fines increased from 2.5 to $40 \%$. Pellet quality can be affected by diet moisture and ingredients. Moisture serves as lubricant reducing the pelleting friction between the feed and the die (Stoch et al., 1981).

However, not without a threshold as it has been proven, that initial mash moisture of $14 \%$ resulted in the most efficient mill operation paired with the highest quality pellet (Muirhead, 1999). In more recently it has been proven that conditioned mash moistures of up to $17 \%$ are beneficial (Feed Pelleting Reference Guide).

Finding the most affordable ingredient sources without sacrificing performance is a common goal among producers. Liquid lactose is a byproduct of the cheese making process and its potential value as a feed ingredient has not been adequately studied. Although, liquid feed products are most common in cattle diets, this byproduct could be utilized as carbohydrate source when formulating swine diets. Liquid lactose as a feed ingredient can affect pellet quality because of its high moisture and sugar contents. This byproduct could serve as a carbohydrate alternative in swine diets, as long as pellet quality is maintained and pig performance is not negatively impacted. 
It is hypothesized that liquid lactose can be used to improve pellet quality leading to improved pig performance. Thus, the objective is to determine the effects of adding liquid lactose to pelleted swine diets on pellet quality and growing-finishing pig performance and carcass characteristics.

\section{Materials and methods}

Texas A\&M University Institutional Animal Care and Use Committee approved the protocol used in this experiment. The study was conducted at Texas A\&M University, O.D. Butler Animal Science Teaching, Research and Extension Center (College Station, TX).

A total of 289 finishing pigs (Line $241 \times 600$; DNA Genetics, Columbus, NE; initially $53.5 \pm 0.5 \mathrm{~kg} \mathrm{BW}$ ) from 3 groups of pigs were used in a $53 \mathrm{~d}$ trial. Treatment was replicated equally in all three groups of pigs. Pigs were housed on solid concrete pens in a fully open sided barn throughout the duration of the experiment. There were 8 pens per group. Pens were equipped with nipple waterers and stainless steel feeders for ad libitum access to water and feed. Pigs were assigned to pens balanced by BW and gender with 8 to 14 pigs per pen. Group 1 pens contained 6 barrows and 8 gilts for 108 total pigs. Group 2 pens contained 6 to 8 barrows and 6 to 7 gilts per pen for 107 total pigs. Group 3 pens contained 3 to 4 barrows and 5 to 7 gilts per pen for a total of 74 pigs. Pens of pigs were allotted to 1 of 4 dietary treatments balanced by BW, number of barrow and gilts per pen, and within group. Dietary treatments were blocked by location

within each group. Overall, there were 6 pens per treatment. Dietary treatments consisted 
of a control diet with 0, 2.5, 5 and 7.5\% liquid lactose (SweetLac 63; Westway Feed Products, Tomball, TX), respectively. Pigs were fed dietary treatments for 53 days in 3 phases. Groups 1 and 3 were fed each phase: d 0 to 19 ; d 19 to 36, and d 36 to 53 . Group 2 was fed each phase: d 0 to 21 ; d 21 to 36 , and d 36 to 53.

All diets were formulated and balanced for SID Lys and fed in pelleted form. The liquid lactose source used contained $31.7 \%$ moisture. Therefore, diets were formulated under the assumption that additional moisture from liquid lactose would be removed during the pellet cooling process (Table 1). Concentration of diet components were initially decreased to allow for moisture loss during the pelleting process. After the pelleting process, components were returned to expected levels. Two batches of all diets were pelleted at a commercial feed mill, and pelleted using a Sprout $26 \mathrm{~W}$ pellet mill. Pellets were steam conditioned to a target of $85^{\circ} \mathrm{C}$, however conditioning temperatures of approximately only $37.8^{\circ} \mathrm{C}$ were achieved because of additional moisture provided by liquid lactose ingredient. Samples were collected when feed was added to the feeder during each phase and then analyzed for percentage fines and pellet durability index (PDI).

Percentage fines were determined before testing pellets for durability. Samples were sifted using a number-6 screen $(3.35 \mathrm{~mm})$. The amount of fines was then weighed and percentage fines were calculated using the following formula: weight of fines/weight of sample $\times 100$. Pellet durability index $(\mathrm{PDI})$ was determined using both the tumble box (ASAE S269.4; ASAE, 1991) and Holmen methods. For the tumble box method, a Seedburo Pellet Durability Tester with $4,0.3 \mathrm{~m} \times 0.14 \mathrm{~m} \times 0.3 \mathrm{~m}$ tumble chambers was 
used. The 500-g samples of pellets were placed in the tumble box and tumbled for 10 minutes. After 10 min, pellets were removed from the tumble box and re-sifted using the number-6 screen $(3.35 \mathrm{~mm})$ and remaining pellets were weighed. Pellet durability was determined by the weight of the sifted pellets after tumbling/weight of the pellets before tumbling $\times 100$. As an additional measurement of pellet durability, the Holman NHP100 (Tekpro Limited, Norfolk, UK) procedure was performed at 60 and $120 \mathrm{~s}$ using forced air agitation to disrupt pellets, simulating breakage from mill to consumption.

On d 53, pigs were shipped approximately 332 miles to a commercial abattoir for harvest and to determine carcass measurements. Pigs were killed on d 54 and hot carcass weights (HCW) were measured, including the head of the carcass. Carcasses were allowed to chill overnight and fat thickness and loin eye area were measured. Fat thickness measurements were measured using a backfat ruler and included first rib, last rib, last lumbar vertebra, and tenth rib fat thickness (10th RFT). Loin eye area (LEA) was measured using a grid. Carcass yield and percent fat free lean (FFL) were calculated (NPPC, 2001). Carcass yield was calculated by dividing the HCW at the plant by the live weight at the farm before transport to the plant. Fat free lean equation was provided by National Pork Board/American Meat Science Association.

\section{Statistical analysis}

Pelleting data were analyzed as a generalized random complete block design with batch as experimental unit. Dietary treatments were fixed effects and phase was considered a random effect. Growth and carcass data were analyzed as a generalized 
random complete block design using PROC MIXED in SAS (SAS Institute, Inc., Cary, NC) with pen as experimental unit. Dietary treatments were used as a fixed effect. Location block within group was used as a blocking factor and considered a random effect. Treatment means were separated using LSMEANS statement of SAS. In addition, data were analyzed for linear and quadratic effects of increasing liquid lactose concentrations. Results from experiment were considered significant at $P<0.05$ and a tendency between $P>0.05$ and $P \leq 0.10$.

Results

Two batches of the experimental diets were pelleted thus an average value was established for chemical analysis of experimental diets (Table B3). Results of diet analysis were similar to formulated values. Increasing liquid lactose in the diet improved (linear, $P<0.01)$ pellet PDI for all methods (Table B4).

For $\mathrm{d} 0$ to 53, there were no differences in ADG, ADFI, G:F or final BW in pigs fed increasing levels of liquid lactose (Table B5). There was tendency (quadratic, $P=$ 0.07 ) for G:F to increase in pigs fed increasing levels of liquid lactose. Pigs fed $2.5 \%$ liquid lactose had the numerically greatest G:F. Additionally, there were no differences in HCW, yield, fat, or muscle measurements between pigs fed dietary treatments (Table B6).

In conclusion, pellet quality was improved by increasing liquid lactose in the diet. There was a tendency for improved feed efficiency, with pigs fed diets containing $2.5 \%$ liquid lactose having optimal feed efficiency. 


\section{Discussion}

Potential advantages to pelleting swine diets include improved animal performance through increased bulk density, and reduced selective feeding, reduced feed waste, and decreases in harmful pathogens present (Behnke, 1994). However this comes with the disadvantage of reduced production rate and increased cost associated with pelleting diets. Previous research demonstrated that pigs fed the pelleted diets had a 3\% greater $\mathrm{ADG}$ and 5\% improvement in G:F compared to those fed meal diets. However, these improvements diminished as pellet quality decreased.

Pellet quality is affected by moisture content and ingredient formulation. A recent study observed the benefits of conditioned mash moisture in pelleted diets up to 17\% (Feed Pelleting Reference Guide). The combinations of heat, hydration and shear during pelleting disrupts starch molecules causing gelatinization improving pellet durability and digestibility (Fahey, Reese et al., 2000). In the experiment herein, increasing liquid lactose in the diet improved pellet quality with all measures of PDI.

Literature suggests that pelleting diets improves G:F but there has been varying effects on ADFI and ADG. When foundational work is compared, there is an average improvement of $6 \%$ in rate of gain and 6 to $7 \%$ in efficiency of gain for pelleted diets fed to finishing pigs (Fahey and Reese, 2000). Researchers attribute growth performance improvements to increased nutrient digestibility and decreased feed wastage (Wondra et al., 1995). However, pellet quality is also a contributing factor. Stark et al., (1994) conducted a finishing experiment to determine pellet quality effects on finishing pig growth performance. Compared to those fed the meal diet, pigs fed the 
pelleted diet had improved ADG of 3\% and G:F of 5\%. Gain: feed improvements for pigs fed pelleted diets were lost as the amount of fines increased. In the experiment herein, ADG was not effected with only a tendency for G:F improvement.

Many researchers have not found differences in carcass characteristics when compared to pigs fed meal diets (Paulk and Hancock 2015; Nemechek et al., 2016; De Jong et al., 2016). There were no differences in $\mathrm{HCW}$, fat, and muscle measurements between pigs fed dietary treatments in the current study.

\section{Conclusions}

In conclusion, pellet quality was improved with addition of liquid lactose in the diet. There was a tendency for improved feed efficiency, with pigs fed diets containing 2.5\% liquid lactose. Optimal liquid lactose inclusion should be determined with economic consideration. 


\section{CHAPTER IV}

\section{SUMMARY}

Pelleting swine diets has demonstrated benefits for both the swine producer and the feed manufacture. Producers and feed manufacturers are constantly striving to improve pellet quality and find the most affordable ingredient sources without sacrificing pig performance. Results of these experiments indicate that pellet quality can be improved with the addition of liquid lactose to the diet. Hot pellet temperature and production rate decreased when $10 \% \mathrm{LL}$ was added to the diet, with $5 \% \mathrm{LL}$ and $9.4 \% \mathrm{M}$ treatments having intermediate effects. The addition molasses to nursery pig diets had an improvement on PDI pellet quality and decrease in percent fines without negatively impacting pig performance with liquid lactose at 5\% LL and 10\% LL, respectively having intermediate effects. Growth performance and fecal consistency of nursery pigs was not negatively affected with inclusion of liquid lactose or molasses in the diet. However, the current study would suggest that increasing liquid lactose to up to $10 \%$ of the diet would increase nursery pig feed intake from d 0 to 21 post weaning. The data suggests that trends and differences in ADFI may contribute to ADG improvements.

There was a tendency for improved feed efficiency in finishing pigs fed diets containing $2.5 \%$ liquid lactose. More research is needed to troubleshoot challenges of pelleting liquid ingredients. Optimal liquid lactose inclusion should be determined with economic consideration. 


\section{LITERATURE CITED}

ASAE. 1987. Wafers, pellets, crumbles - definitions and methods for determining density, durability, and moisture content. ASAE Standard S269.3, Agricultural Engineers Yearbook of Standards. American Society Agricultural Engineers, p 318.

ASAE. 1997. Cubes, Pellets, and Crumbles--Definitions and Methods for Determining Density, Durability, and Moisture Content. ASAE Standard S269.4. American Society of Agricultural and Biological Engineers, St. Joseph, MI.

ASAE Standards S269.4. In Cubes, Pellets, and Crumbles_-Definitions and Methods for Determining Density, Durability, and Moisture Content; ASAE: St. Joseph, MI, USA, 1998.

Becker and Terrill. 1954. Various carbohydrates in a semipurified diet for the growing pig. Arch. Biochem. Biophys., 50: 399-403.

Becker, D.E, D.E Ullrey, S.W Terrill, R.A Notzold. 1954. Failure of the newborn pig to utilize sucrose Science, 120: 345-346.

Behnke, K.C. 1994. Factors affecting pellet quality. Maryland Nutrition Conference. Dept. of Poultry Science and Animal Science, College of Agriculture, University of Maryland, College Park, p 1-11.

Bolin, T. D., R. C. Pirola and A. E. Davis. 1969. Adaptation of intestinal lactose in the rat. Gastroenterology 57: 406.

Briggs, J.L., D.E. Maier, B.A. Watkins, and K.C. Behnke. 1999. Effects of ingredients and processing parameters on pellet quality. Poult. Sci. 78: 1464-1471. 
Carter, S. and C. V. Maxwell. 2000. Feeding the Weaned Pig. Swine Nutrition, Second Edition, CRC Press. 31: 691-715.

Cavalcanti, W.B. and K.C. Behnke. 2005a. Effect of Composition of Feed Model Systems on Pellet Quality: A Mixture Experimental Approach. I. Cereal Chem. 82(4): 455-461.

Cavalcanti, W.B. and K.C. Behnke. 2005b. Effect of Composition of Feed Model Systems on Pellet Quality: A Mixture Experimental Approach. II. Cereal Chem. 82(4): 462-467.

Combs, G.E., Jr. and H.D. Wallace. 1973. Utilization of high dietary levels of cane molasses by young and growing finishing swine, Anim. Sci., res Rep. 49, No. $73-$ 1, Anim. Science Department, University of Florida, Gainsville.

Dahlqvist, A. 1961. Intestine carbohydrase of a newborn pig. Nature 190: 31-32.

De Jong, J. A., J. M. DeRouchey, M. D. Tokach, S. S. Dritz, R. D. Goodband, J. C. Woodworth, and M. W. Allerson. 2016. Evaluating pellet and meal feeding regimens on finishing pig performance, stomach morphology, and carcass characteristics. J. Anim. Sci. 94:4781-4788.

Dritz, S. S., M.D. Tokach, J. L. Nelssen, R. D. Goodband, and L. J. Katz. 1993. Optimal whey level in starter diets containing spray dried blood meal and comparison of avian and bovinespray dried blood meal, J. Anim. Sci., 71(Suppl. 1):56 (Abstr).

Fahey, G. C., et al. 2000. Nonstarch Polysaccharides and Oligosaccharides in Swine Nutrition. Swine Nutrition, Second Edition, CRC Press. 7: 107-130. 
Fahrenholz, A.C. 2012. Evaluating Factors Affecting Pellet Durability and Energy

Consumption in a Pilot Feed Mill and Comparing Methods for Evaluating Pellet Durability. PhD Dissertation. Kansas State Univ., Manhattan, KS.

Fairfield, D., H. Thomas, R. Garrison, J. Bliss, K. Behnke, and A. Gilpin. 2005.

Pelleting. Feed Manufacturing Technology. 5th ed. E. K. Schofield, American Feed Industry Association, Inc., Arlington, VA. p. 142.

Flores, C. A., P. M. Brannon, S. A. Bustamante, J. Bezerra, K. T. Butler, T. Goda, and O. Koldovský. 1988. Effect of diet on intestinal and pancreatic-enzyme activities in the pig. J. Pediatr. Gastroenterol. Nutr. 7: 914-921.

Gilpin, A.S., T.J. Herrman, K.C. Behnke, and F.J. Fairchild. 2002. Feed Moisture, Retention Time, and Steam as Quality and Energy Utilization Determinants in the Pelleting Process. App. Eng. in Ag. 18(3): 331-338.

Guo, J. Y., C. E. Phillips, M. T. Coffey, and S. W. Kim. 2015. Efficacy of a supplemental candy coproduct as an alternative carbohydrate source to lactose on growth performance of newly weaned pigs in a commercial farm condition. J. Anim. Sci. 93:5304-5312.

Hancock, J. and K. Behnke. 2000. Use of Ingredient and Diet Processing Technologies (Grinding, Mixing, Pelleting, and Extruding) to Produce Quality Feeds for Pigs. Swine Nutrition, Second Edition, CRC Press. 21: 469-497.

Heilskov, N. S. C. 1951. Studies on animal lactase. I. Lactase activity determination. Acta Physiol. Scand. 22:267-276. 
Hendriks, W.H., Moughan, P.J., Boer, H., van der Poel, A.F.B. 1994. Effects of extrusion on the dye-binding, fluorodinitrobenzene-reactive and total lysine content of soya-bean meal and peas. Anim. Feed Sci. Technol. 48: 99-109.

Jones, C.K., C.R. Stark, and A.C. Fahrenholz, eds. Feed Pelleting Reference Guide. Illinois: WATT Ag Net. 2014. Electronic. Retrieved from: http://www.wattagnet.com/feed-pelleting-reference-guide.

Kelly, D., J. A. Smyth, and K. J. Mccracken. 1991a. Digestive development of the earlyweaned pig. 1. Effect of continuous nutrient supply on the development of the digestive tract and on changes in digestive enzyme activity during the 1st week post-weaning. Br. J. Nutr. 65:169-180.

Klobasa, F., E. Werhahn, and J. E. Butler. 1987. Composition of Sow Milk During Lactation. J. Anim. Sci. 64:1458-1466.

Lawlor, P. G., P. B. Lynch, G. E. Gardiner, P. J. Caffrey, and J. V. O’Doherty. 2002. Effect of liquid feeding weaned pigs on growth performance to harvest. Journal of Animal Science. 80:1725-1735.

Loeza, R. D.H. Beeman, X. G. Lei, K. Roneker, and R. W. Blake 1997. Effect of cane molasses in diets for finishing pigs, J. Anim. Sci., 75 (Suppl 1):129.

Ly, J. 1996. The pattern of digestion and metabolism in high sugar feeds for pigs. Cuban J. Agric. Sci. 30:117-129.

Mahan, D. C., 1993. Evaluating two sources of dried whey and the effects of replacing the corn and dried whey component with corn gluten meal and lactose in the diets of weanling swine. J. Anim. Sci. 71 (11): 2860-2866. 
Mahan, D. C., N. D. Fastinger, and J. C. Peters. 2004. Effects of diet complexity and dietary lactose levels during three starter phases on postweaning pig performance. J. Anim. Sci. 82:2790-2797.

Manners, M. J., and J. A. Stevens. 1972. Changes from birth to maturity in the pattern of distribution of lactase and sucrase activity in the mucosa of small intestine in pigs. Br. J. Nutr. 28:113-127.

Mavromichalis, I., J. D. Hancock, R. H. Hines, B. W. Senne, and H. Cao. 2001. Lactose, sucrose, and molasses in simple and complex diets for nursery pigs. Anim. Feed Sci. Technol. 93:127-135.

McCoy, R.A., 1992. Effect of mixing uniformity on broiler chick performance. Master's thesis, Kansas State Univ., Manhattan, KS.

Moser, R. L., E. R. Peo, T.D. Crenshaw, and P. J. Cunningham. 1980. Effect of Dietary Lactose on Gain, Feed Conversion, Blood, Bone and Intestinal Parameters in Postweaning Rats and Swine. J. Anim. Sci. 51:89-99.

Motai, H., 1976. Viscosity of melanoidins formed by oxidative browning. Validity of the equation for a relationship between color intensity and molecular weight of melanoidin. J. Agricultural and Biological Chemistry. 40: 1-7.

Muirhead, S. 1999. Precision in Mash Moisture Management Improves Pellet. Feedstuffs 71(10):16.

Myer, R. and J. Brendemuhl 2000. Miscellaneous Feedstuffs. Swine Nutrition, Second Edition, CRC Press. 37: 839-864. 
National Research Council (NRC). 2012. Nutrient Requirements of Swine. National Academy Press, Washington, DC.

Nemechek, J. E., M. D. Tokach, S. S. Dritz, E. D. Fruge, E. L. Hansen, R. D. Goodband, J. M. DeRouchey, and J. C. Woodworth. 2015. Effects of diet form and feeder adjustment on growth performance of nursery and finishing pigs. J. Anim. Sci. 93:4172-4180.

Nemechek, J. E., M. D. Tokach, S. S. Dritz, R. D. Goodband, J. M. DeRouchey, and J. C. Woodworth. 2015. Effects of diet form and type on growth performance, carcass yield, and iodine value of finishing pigs. J. Anim. Sci. 93:4486-4499.

Nemechek, J. E., M. D. Tokach, S. S. Dritz, R. D. Goodband, J. M. DeRouchey, and J. C. Woodworth. 2016. Effects of diet form and corn particle size on growth performance and carcass characteristics of finishing pigs. Anim. Feed Sci. Technol. 214:136-141.

Nessmith, W. B., J. L. Nelssen, M. D. Tokach, R. D. Goodband, and J. R. Bergström. 1997. Effects of substituting deproteinized whey and (or) crystalline lactose for dried whey on weanling pig performance. Journal of Animal Science 75:32223228.

Nordstrom, C., and A. Dahlqvist. 1973. Quantitative distribution of some enzymes along villi and crypts of human small intestine. Scand. J. Gastroenterol. 8:407-416.

NPPC 2001. Procedures for Estimating Pork Carcass Composition. Natl. Pork Prod. Counc., Des Moines, IA. 
Owen K. Q., J.L. Nelssen, M. D. Tokach, R. D. Goodband, S. S. Dritzand L. J. Katz. 1993b. The effect of increasing level of lactose in a porcine plasma-based diet for the early weaned pig, J. Anim. Sci. 71(Suppl. 1): 175 (Abstr.).

Paulk, C. B. 2011. Manipulation of processing technologies to enhance growth performance and (or) reduce production costs in pigs. M.S. Thesis Kansas State Univ., Manhattan, KS.

Paulk, C. B., and J. D. Hancock. 2015. Effects of an abrupt change between diet form on growth performance in finishing pigs. Anim. Feed Sci. Technol. 211:132-136.

Remsen CH, Clark JP. 1978. A viscosity model for a cooking dough. J Food Process Eng 2(1):39-64.

Richert, B. and T. Cline. 2000. Feeding Growing-Finishing Pigs. Swine Nutrition, Second Edition, CRC Press. 32: 717- 723.

Schell, T. C., and E. van Heugten. 1998. The effect of pellet quality on growth performance of grower pigs. J. Anim. Sci. 76(suppl. 1) 717 (Abstr.).

Skoch, E. R., K. C. Behnke, C. W. Deyoe, and S. F. Binder, 1981.The effect of steam conditioning rate on the pelleting process. Anim. Feed Sci. Technol. 6:83.

Smiricky, M. R., C. M. Grieshop, D. M. Albin, J. E. Wubben, V. M. Gabert, and G. C. Fahey. 2002. The influence of soy oligosaccharides on apparent and true ileal amino acid digestibilities and fecal consistency in growing pigs. Journal of Animal Science 80:2433-2441. 
Stark, C. R. 1994. Pellet quality and its effect on swine performance; functional characteristics of ingredients in the formation of quality pellets. Ph.D. Dissertation. Kansas State Univ., Manhattan, KS.

Stark, C. R. 2009. Effect of die thickness and pellet mill throughput on pellet quality. Abstr. T89. Southern Poultry Science Society Meeting.

Stark, C. R., K. C. Behnke, J. D. Hancock, S. L. Traylor, and R. H. Hines. 1994. Effect of diet form and fines in pelleted diets on growth performance of nursery pigs. $\mathrm{J}$. Anim. Sci. 72 (Suppl. 1): 825 (Abstr.).

Stephas, E. L., and B.L. Miller, 1998. Evaluation of dextrose as a replacement for crystalline lactose in phase I and phase II nursery diets. Journal of Animal Science 76 (Suppl. 1), 66 (Abstr.).

Thomas M., T. van Vliet, A.F.B. van der Poel. 1998. Physical quality of pelleted animal feed 3. Contribution of feedstuff components, Animal Feed Science and Technology. 70(1): 59-78.

Tokach, M. D., R. D. Goodband, and J. L Nelsson. 1994. Recent developments in nutrition for early-weaned pig. The compendium on Continuing Education. 18 (3):407:2790-2797.

Touchette, K. J., S. D. Crow, G. L. Allee, and M. D. Newcomb. 1995. Weaned pigs respond to lactose (day 0-14 postweaning). J. Anim. Sci. 73(Suppl. 1):70 (Abstr.). 
Van Bameveld, R.J., 1993. Effect of heating proteins on the digestibility, availability and utilisation of lysine by growing pigs. PhD Thesis, University of Queensland, Australia. Biol. Chem. 40: I-7.

Van den Berg, C., 1992. Glass transitions in carbohydrates. Carbohydrates in the Netherlands. 8: 23-25.

Wondra, K. J., J. D. Hancock, K. C. Behnke, R. H. Hines, and C. R. Stark. 1995. Effects of particle size and pelleting on growth performance, nutrient digestibility, and stomach morphology in finishing pigs. J. of Anim. Sci. 73:757-763.

Yang, H., J. A. Kerber, J. E. Pettigrew, L. J. Johnston and R. D. Walker. 1997. Evaluation of milk chocolate product as a substitute for whey in pig starter diets, J. Anim. Sci. 75:423

Yasutake, H., T. Goda, and S. Takase. 1995. Dietary regulation of sucrase-isomaltase gene expression in rate jejunum. Biochim. Biophys. Acta 1243:270-276. 
Table A2: Formulated diet composition (as-fed) basis ${ }^{1}$

\begin{tabular}{|c|c|c|c|c|c|c|c|c|c|}
\hline \multirow[b]{2}{*}{ Item } & \multicolumn{4}{|c|}{ Phase 1} & \multicolumn{4}{|c|}{ Phase 2} & \multirow{2}{*}{$\begin{array}{c}\text { Phase } 3 \\
\text { Common Diet }\end{array}$} \\
\hline & Control & $5 \% \mathrm{LL}^{2}$ & $10 \% \mathrm{LL}$ & $9.4 \% \mathrm{M}^{3}$ & Control & $5 \% \mathrm{LL}$ & $10 \% \mathrm{LL}$ & $9.4 \% \mathrm{M}$ & \\
\hline \multicolumn{10}{|l|}{ Ingredient, \% } \\
\hline Corn & 31.97 & 30.64 & 29.34 & 29.03 & 31.49 & 30.24 & 28.87 & 28.57 & 50.90 \\
\hline Soybean Meal, 46.5\% & 29.33 & 28.93 & 28.48 & 28.88 & 30.07 & 29.60 & 29.19 & 29.55 & 25.84 \\
\hline Corn DDGS & 5.00 & 4.93 & 4.85 & 4.92 & 20.00 & 19.72 & 19.42 & 19.67 & 20.00 \\
\hline Fish Meal Combined & 5.00 & 4.93 & 4.85 & 4.92 & --- & --- & --- & --- & --- \\
\hline Milk, Whey Powder & 12.50 & 12.32 & 12.14 & 12.30 & 7.50 & 7.39 & 7.28 & 7.38 & --- \\
\hline Milk, Whey Permeate, $85 \%$ & 11.25 & 8.38 & 5.58 & 5.80 & 5.50 & 2.71 & 0.00 & 0.15 & --- \\
\hline SweetLac 63 & 0.00 & 5.00 & 10.00 & --- & --- & 5.00 & 10.00 & --- & --- \\
\hline Molasses Cane & --- & --- & --- & 9.40 & --- & --- & --- & 9.40 & --- \\
\hline Soybean oil & 2.00 & 1.97 & 1.94 & 1.97 & 2.00 & 1.97 & 1.94 & 1.97 & --- \\
\hline Monocalcium phosphate, $21 \% \mathrm{P}$ & 0.50 & 0.44 & 0.36 & 0.57 & 0.95 & 0.89 & 0.83 & 1.03 & 0.95 \\
\hline Limestone, ground & 0.85 & 0.86 & 0.87 & 0.62 & 1.00 & 0.99 & 1.00 & 0.76 & 1.15 \\
\hline Sodium chloride & 0.30 & 0.30 & 0.29 & 0.30 & 0.35 & 0.35 & 0.34 & 0.34 & 0.35 \\
\hline L-Lys-HCL & 0.33 & 0.33 & 0.33 & 0.34 & 0.40 & 0.40 & 0.40 & 0.41 & 0.40 \\
\hline DL-Met & 0.18 & 0.18 & 0.18 & 0.18 & 0.13 & 0.12 & 0.13 & 0.13 & 0.06 \\
\hline L-Thr & 0.14 & 0.14 & 0.14 & 0.14 & 0.12 & 0.11 & 0.11 & 0.12 & 0.09 \\
\hline L-Trp & --- & --- & --- & --- & --- & --- & 0.01 & 0.01 & 0.00 \\
\hline VTM Premix ${ }^{4}$ & 0.25 & 0.25 & 0.24 & 0.25 & 0.25 & 0.25 & 0.24 & 0.25 & 0.25 \\
\hline Phytase ${ }^{5}$ & 0.01 & 0.01 & 0.01 & 0.01 & 0.01 & 0.01 & 0.01 & 0.01 & 0.01 \\
\hline Zinc oxide & 0.40 & 0.39 & 0.39 & 0.39 & 0.25 & 0.25 & 0.24 & 0.25 & --- \\
\hline Total & 100 & 100 & 100 & 100 & 100 & 100 & 100 & 100 & 100 \\
\hline \multicolumn{10}{|l|}{ Calculated analysis } \\
\hline \multicolumn{10}{|c|}{ Standard ileal digestible (SID) AA,\% } \\
\hline Lys & 1.44 & 1.44 & 1.44 & 1.44 & 1.35 & 1.35 & 1.35 & 1.35 & 1.20 \\
\hline Ile:Lys ratio & 60 & 60 & 60 & 60 & 64 & 63 & 63 & 63 & 64 \\
\hline Leu:Lys ratio & 117 & 116 & 115 & 115 & 138 & 137 & 136 & 136 & 150 \\
\hline Met:Lys ratio & 36 & 37 & 36 & 36 & 34 & 34 & 34 & 34 & 32 \\
\hline Met+Cys:Lys ratio & 57 & 57 & 57 & 57 & 57 & 57 & 57 & 57 & 56 \\
\hline Thr:Lys ratio & 63 & 63 & 63 & 63 & 63 & 63 & 63 & 63 & 62 \\
\hline Trp:Lys ratio & 18.1 & 17.9 & 17.7 & 17.6 & 18.2 & 18.2 & 18.2 & 18.2 & 17.3 \\
\hline Val:Lys ratio & 65 & 65 & 65 & 65 & 70 & 70 & 70 & 69 & 72 \\
\hline Total Lys,\% & 1.61 & 1.61 & 1.61 & 1.61 & 1.54 & 1.54 & 1.54 & 1.54 & 1.39 \\
\hline ME. Kcal/kg & 3,430 & 3,406 & 3,380 & 3,157 & 3,393 & 3,369 & 3,342 & 3,117 & 3283 \\
\hline $\mathrm{NE}, \mathrm{kcal} / \mathrm{kg}$ & 2,383 & 2,282 & 2,180 & 2,167 & 1,969 & 1,870 & 1,768 & 1,753 & 855 \\
\hline SID Lys: ME ratio, $\mathrm{g} / \mathrm{mcal}$ & 1.48 & 1.47 & 1.46 & 1.36 & 1.34 & 1.33 & 1.32 & 1.23 & 1.25 \\
\hline $\mathrm{CP}, \%$ & 23.5 & 23.4 & 23.4 & 23.6 & 24.0 & 23.9 & 23.9 & 24.1 & 22.5 \\
\hline Crude fat, \% & 4.6 & 4.6 & 4.7 & 4.5 & 5.3 & 5.4 & 5.5 & 5.3 & 3.9 \\
\hline Crude fiber, $\%$ & 2.2 & 2.2 & 2.2 & 2.2 & 3.6 & 3.6 & 3.5 & 3.5 & 3.8 \\
\hline $\mathrm{Ca}, \%$ & 0.82 & 0.82 & 0.82 & 0.82 & 0.70 & 0.70 & 0.70 & 0.70 & 0.64 \\
\hline
\end{tabular}


Table A2: (continued)

$$
\text { P, } \%
$$

$0.70 \quad 0.70$

Available P, \%

$\begin{array}{ll}0.70 & 0.70 \\ 0.45 & 0.45\end{array}$

0.70

0.70
0.45

$\begin{array}{ll}0.78 .7 & 18.2\end{array}$

Sugar, \%

$18.7 \quad 18.7$

$\begin{array}{ll}0.70 & 0.70 \\ 0.45 & 0.45\end{array}$

17.8

0.45
14.1

$\begin{array}{llll}0.69 & 0.69 & 0.69 & 0.69 \\ 0.43 & 0.43 & 0.43 & 0.43\end{array}$

0.69
0.43
5.6

$\begin{array}{rrrr}10.1 & 9.7 & 9.2 & 5.6 \\ 10.1 & 10.1 & 10.1 & 10.1\end{array}$

0.64

${ }^{1}$ Treatment diets were fed during phase 1 from $\mathrm{d} 0$ to 7 and phase 2 from $\mathrm{d} 7$ to 21 , with a common phase 3 diet fed from d 21

were fed in pelleted form

${ }^{2} \mathrm{LL}=$ SweetLac (SweetLac 63; Westway Feed Products, Tomball, TX).

${ }^{3} \mathrm{M}=$ Sugar Cane Molasses.

${ }^{4}$ VTM = vitamin and trace mineral premix, which provide per kilogram premix: 725,747 IU vitamin A, 136,078 IU vitamin D, 3,629 IU vitamin

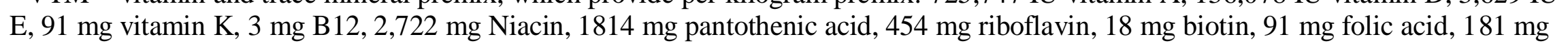

pyridoxine, 3,005ppm Zn phase 1, 1,925 ppm Zn phase 2, $125 \mathrm{ppm} \mathrm{Zn}$ phase 3, 125ppm Fe, $22 \mathrm{ppm} \mathrm{Mg}, 15 \mathrm{ppm} \mathrm{Cu}, 0.6 \mathrm{ppm} \mathrm{I}, 0.3 \mathrm{ppm} \mathrm{Se}$

RONOZYME HiPhos 2,700 provided 201 phytase units (FYT)/kg with a release of $0.05 \%$ available $\mathrm{P}$. 
Table A3: Chemical Analysis of Experimental Diets (as-fed) ${ }^{1}$

\begin{tabular}{|c|c|c|c|c|c|c|c|c|c|}
\hline \multirow[b]{2}{*}{ Item, $\%$} & \multicolumn{4}{|c|}{ Phase 1} & \multicolumn{4}{|c|}{ Phase 2} & \multirow{2}{*}{$\begin{array}{c}\text { Phase } 3 \\
\text { Common Diet }\end{array}$} \\
\hline & Control & $5 \% \mathrm{LL}^{2}$ & $10 \% \mathrm{LL}$ & $9.4 \% \mathrm{M}^{3}$ & Control & $5 \% \mathrm{LL}$ & $10 \% \mathrm{LL}$ & $\begin{array}{c}9.4 \% \\
\mathrm{M} \\
\end{array}$ & \\
\hline \multicolumn{10}{|l|}{ Mash } \\
\hline Moisture $^{4}$ & 9.12 & 10.25 & 12.03 & 11.51 & 10.74 & 11.23 & 12.89 & 12.27 & --- \\
\hline \multicolumn{10}{|l|}{ Pellet $^{5}$} \\
\hline Moisture & 9.9 & 10.3 & 11.9 & 11.5 & 8.8 & 10.4 & 11.8 & 11.4 & 11.7 \\
\hline $\begin{array}{l}\text { Dry Matter } \\
\text { Crude Protein }\end{array}$ & $\begin{array}{l}90.1 \\
23.6\end{array}$ & $\begin{array}{l}89.7 \\
23.2\end{array}$ & $\begin{array}{l}88.1 \\
23.3\end{array}$ & $\begin{array}{l}88.5 \\
23.8\end{array}$ & $\begin{array}{l}91.2 \\
23.5\end{array}$ & $\begin{array}{l}89.6 \\
24.9\end{array}$ & $\begin{array}{l}88.2 \\
23.9\end{array}$ & $\begin{array}{l}88.6 \\
23.4\end{array}$ & $\begin{array}{l}88.3 \\
22.2\end{array}$ \\
\hline $\begin{array}{l}\text { Crude Fiber } \\
\text { Ethanol Soluble CHO (Sugar) }\end{array}$ & $\begin{array}{r}3.2 \\
11.6\end{array}$ & $\begin{array}{r}3.0 \\
12.6\end{array}$ & $\begin{array}{r}3.3 \\
12.6\end{array}$ & $\begin{array}{r}2.9 \\
14.4\end{array}$ & $\begin{array}{r}3.9 \\
13.1\end{array}$ & $\begin{array}{r}4.3 \\
11.0\end{array}$ & $\begin{array}{r}4.3 \\
11.1\end{array}$ & $\begin{array}{r}4.3 \\
12.9\end{array}$ & $\begin{array}{l}4.2 \\
4.3\end{array}$ \\
\hline Crude Fat & 4.1 & 4.5 & 4.5 & 4.0 & 4.7 & 4.8 & 4.6 & 4.7 & 3.1 \\
\hline Ash & 7.4 & 7.9 & 7.7 & 7.7 & 7.8 & 7.2 & 8.0 & 7.6 & 5.8 \\
\hline Calcium & 0.9 & 1.0 & 0.9 & 0.9 & 1.2 & 1.0 & 1.0 & 0.9 & 0.7 \\
\hline Phosphorus & 0.7 & 0.7 & 0.7 & 0.7 & 0.8 & 0.7 & 0.7 & 0.7 & 0.7 \\
\hline Non Fiber Carbohydrates & 55.1 & 54.0 & 52.7 & 53.0 & 55.2 & 52.7 & 51.6 & 53.0 & 57.3 \\
\hline Non Structural Carbohydrates & 11.6 & 12.6 & 12.6 & 14.4 & 13.1 & 11.0 & 11.1 & 12.9 & 4.3 \\
\hline
\end{tabular}

\footnotetext{
${ }^{1}$ Liquid lactose product was obtained by Westway Feed Products (Tomball, TX).

${ }^{2}$ LL = (SweetLac 63; Westway Feed Products, Tomball, TX).

${ }^{3} \mathrm{M}=$ Sugar Cane Molasses.

${ }^{4}$ Moisture of the experimental mash diets that were pelleted.

${ }^{5}$ Pellet samples were analyzed at Cumberland Valley Analytical Services (Hagerstown, MD).
} 
Table A 4: Pellet Quality of Experimental Diets

\begin{tabular}{|c|c|c|c|c|c|c|}
\hline It e m & Control & $5 \% \mathrm{LL}^{1}$ & $10 \% \mathrm{LL}$ & $9.4 \% \mathrm{M}^{2}$ & S E M & Probability, $P<$ \\
\hline Hot Pellet & $69.44^{b}$ & $62.6^{\mathrm{ab}}$ & $59.36^{\mathrm{a}}$ & $63.56^{\mathrm{ab}}$ & 7.993 & 0.0417 \\
\hline Temperature, ${ }^{\circ} \mathrm{C}^{5}$ & & & & & & \\
\hline $\begin{array}{l}\text { Production Rate, } \\
(\text { metrictons/hr })^{6}\end{array}$ & $0.44^{\mathrm{b}}$ & $0.43^{\mathrm{ab}}$ & $0.39^{\mathrm{a}}$ & $0.41^{\mathrm{ab}}$ & 0.016 & 0.0300 \\
\hline Fines, $\%^{3}$ & $6.96^{\mathrm{c}}$ & $3.93^{\mathrm{b}}$ & $3.01^{\mathrm{b}}$ & $1.84^{\mathrm{a}}$ & 1.134 & 0.0128 \\
\hline $\mathrm{P} \mathrm{D} \mathrm{I}, \% 4$ & $93.04^{\mathrm{a}}$ & $96.08^{\mathrm{bc}}$ & $96.99^{\mathrm{cd}}$ & $98.17^{\mathrm{d}}$ & 1.134 & 0.0128 \\
\hline Holmen $60, \%^{5}$ & $87.10^{\mathrm{a}}$ & $91.63^{\mathrm{b}}$ & $94.80^{\mathrm{cd}}$ & $96.43^{\mathrm{d}}$ & 1.214 & 0.0012 \\
\hline Holmen $120, \%$ & $74.70^{\mathrm{a}}$ & $83.45^{\mathrm{b}}$ & $90.65^{\mathrm{c}}$ & $93.65^{\mathrm{d}}$ & 2.146 & 0.0003 \\
\hline
\end{tabular}

${ }^{1} \mathrm{LL}=\mathrm{S}$ weetLac (SweetLac 63; Westway Feed Products, Tomball, TX).

${ }^{2} \mathrm{M}=\mathrm{Sugar} \mathrm{Cane} \mathrm{M}$ olasses.

${ }^{3}$ Hot Pellet Temperatures were recorded with a single probe digital thermometer at the center of

collected sample.

${ }^{4}$ Production rate was measured as the weight of the pellets collected divided by $60 \mathrm{~s}$.

${ }^{5}$ Percentage fines were determined using a number 6 screen $(3.35 \mathrm{~mm})$.

${ }^{6}$ A Seedboro Pellet Durability Tester was used to determine PDI (pellet durability index). Pellets were tumbled in 500 -g samples of feed for $10 \mathrm{~min}$, then, using a number-6 screen ( $3.35 \mathrm{~mm}$ ) fines were sifted from the sample.

7 Holmen NHP 100 (Tekpro Limited, Norfolk, United Kingdom) process was run at 60 and 120 s as an additional PDI parameter, completed at Kansas State University.

a-d Means within a row with different superscripts differ $(P<0.05)$. 
Table A5: Effects of liquid lactose and molasses in nursery pig diets on growth performance ${ }^{1,2,3}$

\begin{tabular}{ccccccc}
\hline Item & Control & $5 \%$ LL & $10 \%$ LL & $9.4 \%$ M & SEM & Probability, P< \\
\hline d 0 to 7 & & & & & & \\
ADG, g & 127 & 133 & 162 & 150 & 24.8 & 0.168 \\
ADFI, g & 196 & 202 & 207 & 193 & 18.7 & 0.656 \\
G:F & $0.604^{\mathrm{a}}$ & $0.622^{\mathrm{a}}$ & $0.736^{\mathrm{b}}$ & $0.753^{\mathrm{b}}$ & 0.067 & 0.022 \\
d 7 to 21 & & & & & & \\
ADG, g & 243 & 270 & 264 & 262 & 17.8 & 0.718 \\
ADFI, g & $371^{\mathrm{a}}$ & $417^{\mathrm{ab}}$ & $454^{\mathrm{b}}$ & $405^{\mathrm{ab}}$ & 19.5 & 0.046 \\
G:F & 0.652 & 0.645 & 0.584 & 0.649 & 0.036 & 0.390 \\
d 21 to 33 & & & & & & \\
ADG, g & $460^{\mathrm{a}}$ & $449^{\mathrm{ab}}$ & $476^{\mathrm{a}}$ & $410^{\mathrm{b}}$ & 25.6 & 0.062 \\
ADFI, g & 674 & 692 & 704 & 633 & 32.8 & 0.192 \\
G:F & 0.683 & 0.652 & 0.675 & 0.643 & 0.017 & 0.296 \\
d 0 to 21 & & & & & & \\
ADG, g & 204 & 224 & 230 & 225 & 17.1 & 0.577 \\
ADFI, g & $312^{\mathrm{a}}$ & $345^{\mathrm{ab}}$ & $372^{\mathrm{b}}$ & $334^{\mathrm{ab}}$ & 17.0 & 0.064 \\
G:F & 0.645 & 0.646 & 0.617 & 0.671 & 0.034 & 0.600 \\
d 0 to 33 & & & & & & \\
ADG, g & 297 & 306 & 320 & 292 & 13.2 & 0.499 \\
ADFI, g & $444^{\mathrm{a}}$ & $471^{\mathrm{ab}}$ & $492^{\mathrm{b}}$ & $443^{\mathrm{a}}$ & 15.8 & 0.109 \\
G:F & 0.667 & 0.649 & 0.650 & 0.660 & 0.017 & 0.807 \\
BW, kg & & & & & & \\
d 7 & 7.62 & 7.64 & 7.85 & 7.79 & 0.089 & 0.148 \\
d 21 & 11.02 & 11.42 & 11.55 & 11.46 & 0.300 & 0.588 \\
d 33 & 16.54 & 16.81 & 17.26 & 16.38 & 0.461 & 0.535 \\
\hline A 19.619 &
\end{tabular}

\footnotetext{
${ }^{1}$ A total of 194 nursery pigs (DNA $241 \times 600$; initially $6.7 \pm 0.4 \mathrm{~kg}$ at $27 \mathrm{~d}$ of age) were used with 8 replicate pens per treatment and 4-7 pig per pen. Research was conducted at Texas A\&M University, O.D. Butler Animal Science Teaching and Research Center, Nutrition and Physiology Center (College Station, TX).

${ }^{2}$ Experimental diets were fed from $\mathrm{d} 0$ to 21 followed by a common diet d 21-33.

${ }^{3}$ Liquid Lactose product was obtained by Westway Feed Products (Tomball, TX).

${ }^{4}$ Control Diet with $19.1 \%$ total sugars from whey powder and whey permeate $(85 \%$ lactose).

${ }^{5} 5 \%$ SweetLac; $12 \%$ of the total sugars replaced by $5 \%$ liquid lactose ( $44.7 \%$ total sugars).

${ }^{6} 10 \%$ SweetLac; $24 \%$ total sugars replaced by $10 \%$ liquid lactose (44.7\% total sugars).

${ }^{7} 9.4 \%$ molasses; $24 \%$ total sugars with $9.4 \%$ molasses.

${ }^{8}$ Sugar Cane Molasses.

${ }^{\mathrm{a}-\mathrm{c}}$ Means within a row with different superscripts differ $(\mathrm{P}<0.05)$.
} 
Table A6: Fecal Consistency and DM, \% on d 7 and 14 of Experimental Diets ${ }^{1}$

\begin{tabular}{ccccccc}
\hline Item & Control & $5 \% \mathrm{LL}^{2}$ & $10 \% \mathrm{LL}$ & $9.4 \% \mathrm{M}^{3}$ & SEM & Probability, $P<$ \\
\hline Score & & & & & & \\
d7 & $3.86^{\mathrm{a}}$ & $4.00^{\mathrm{a}}$ & $3.51^{\mathrm{ab}}$ & $3.15^{\mathrm{b}}$ & 0.213 & 0.030 \\
d14 & 3.88 & 4.05 & 3.95 & 3.72 & 0.123 & 0.297 \\
DM, \% & & & & & & \\
d7 & 16.74 & 16.87 & 19.04 & 20.35 & 2.120 & 0.482 \\
d14 & 15.49 & 13.99 & 14.89 & 16.89 & 0.997 & 0.246 \\
\hline
\end{tabular}

${ }^{1}$ Smiricky (2002); 1 = hard, dry pellet; 2 = firm, formed stool; 3 = soft, moist stool that retains shape; $4=$ soft, moist stool that assumes shape of container, and $5=$ water liquid that can be poured.

${ }^{2}$ LL = SweetLac (SweetLac 63; Westway Feed Products, Tomball, TX).

${ }^{3} \mathrm{M}=$ Sugar Cane Molasses.

${ }^{\mathrm{a}-\mathrm{c}}$ Means within a row with different superscripts differ $(\mathrm{P}<0.05)$. 


\section{APPENDIX B}

\section{CHAPTER III TABLES}

Table B1: Chemical analysis of SweetLac $63^{1}$, liquid lactose product (as-fed basis) ${ }^{2}$

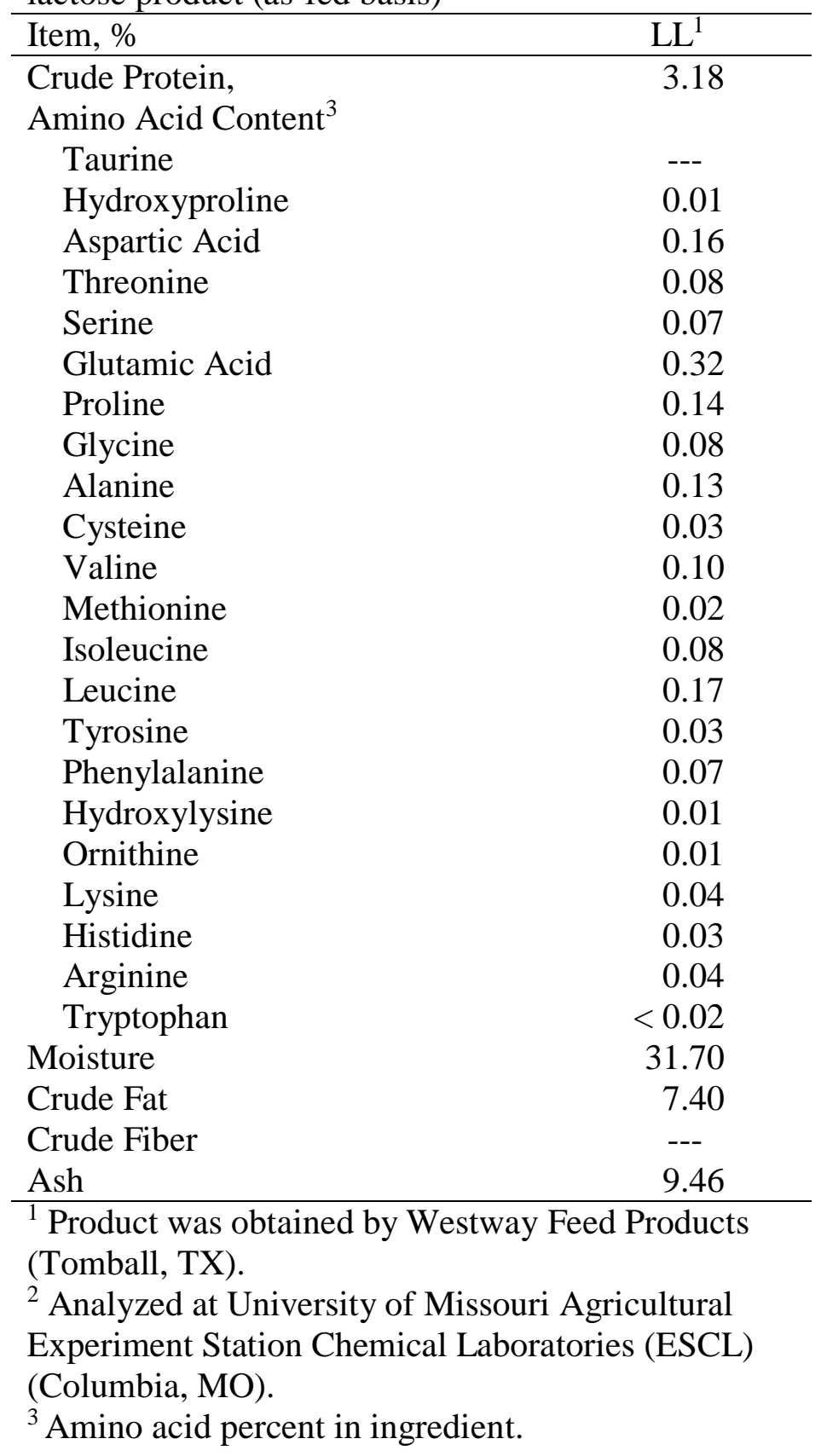


Table B2: Formulated diet composition (as-fed) basis ${ }^{1}$

\begin{tabular}{|c|c|c|c|c|c|c|c|c|c|c|c|c|}
\hline \multirow[b]{2}{*}{ Item } & \multicolumn{4}{|c|}{ Phase 1} & \multicolumn{4}{|c|}{ Phase 2} & \multicolumn{4}{|c|}{ Phase 3} \\
\hline & Control & $2.5 \%^{2}$ & $5 \%{ }^{3}$ & $7.5 \%{ }^{4}$ & Control & $2.5 \%$ & $5 \%$ & $7.5 \%$ & Control & $2.5 \%$ & $5 \%$ & $7.5 \%$ \\
\hline \multicolumn{13}{|l|}{ Ingredient, \% } \\
\hline Corn & 61.36 & 59.43 & 57.51 & 55.59 & 66.26 & 64.34 & 62.42 & 60.50 & 69.20 & 67.28 & 65.35 & 63.43 \\
\hline Soybean Meal, Dehull, Sol Extr & 16.32 & 16.42 & 16.52 & 16.61 & 11.57 & 11.67 & 11.76 & 11.86 & 8.85 & 8.94 & 9.04 & 9.14 \\
\hline Corn DDGS, $>6$ and $<9 \%$ Oil & 20.00 & 20.00 & 20.00 & 20.00 & 20.00 & 20.00 & 20.00 & 20.00 & 20.00 & 20.00 & 20.00 & 20.00 \\
\hline Limestone, ground & 1.43 & 1.43 & 1.43 & 1.43 & 1.28 & 1.28 & 1.28 & 1.28 & 1.10 & 1.10 & 1.10 & 1.10 \\
\hline Sodium chloride & 0.35 & 0.35 & 0.35 & 0.35 & 0.35 & 0.35 & 0.35 & 0.35 & 0.35 & 0.35 & 0.35 & 0.35 \\
\hline L-Lys-HCL & 0.28 & 0.28 & 0.28 & 0.28 & 0.27 & 0.27 & 0.27 & 0.27 & 0.24 & 0.24 & 0.24 & 0.24 \\
\hline VTM Premix 5 & 0.25 & 0.25 & 0.25 & 0.25 & 0.25 & 0.25 & 0.25 & 0.25 & 0.25 & 0.25 & 0.25 & 0.25 \\
\hline Phytase $^{6}$ & 0.02 & 0.02 & 0.02 & 0.02 & 0.02 & 0.02 & 0.02 & 0.02 & 0.02 & 0.02 & 0.02 & 0.02 \\
\hline SweetLac (90\% DM) & --- & 1.83 & 3.65 & 5.48 & --- & 1.83 & 3.65 & 5.48 & --- & 1.83 & 3.65 & 5.48 \\
\hline Total & 100 & 100 & 100 & 100 & 100 & 100 & 100 & 100 & 100 & 100 & 100 & 100 \\
\hline \multirow{2}{*}{\multicolumn{13}{|c|}{ Calculated Analysis }} \\
\hline & & & & & & & & & & & & \\
\hline \multicolumn{13}{|l|}{$\mathrm{AA}, \%$} \\
\hline Lys & 0.87 & 0.87 & 0.87 & 0.87 & 0.75 & 0.75 & 0.75 & 0.75 & 0.66 & 0.66 & 0.66 & 0.66 \\
\hline Ile;Lys ratio & 70 & 70 & 70 & 70 & 71 & 71 & 71 & 71 & 74 & 74 & 74 & 74 \\
\hline Leu:Lys ratio & 181 & 180 & 178 & 177 & 196 & 194 & 192 & 191 & 213 & 211 & 209 & 207 \\
\hline Met:Lys ratio & 32 & 32 & 32 & 32 & 35 & 35 & 34 & 34 & 38 & 37 & 37 & 37 \\
\hline Met+Cys:lys ratio & 62 & 61 & 61 & 60 & 66 & 65 & 65 & 64 & 71 & 71 & 70 & 70 \\
\hline Thr;Lys ratio & 61 & 61 & 61 & 61 & 62 & 62 & 62 & 62 & 65 & 65 & 65 & 65 \\
\hline Trp;Lys ratio & 18 & 18 & 18 & 18 & 17 & 17 & 17 & 17 & 17 & 17 & 17 & 17 \\
\hline Val;Lys ratio & 82 & 82 & 82 & 82 & 85 & 85 & 85 & 85 & 90 & 90 & 90 & 90 \\
\hline Total Lys, $\%$ & 1.03 & 1.03 & 1.03 & 1.03 & 0.90 & 0.90 & 0.90 & 0.90 & 0.80 & 0.80 & 0.80 & 0.80 \\
\hline ME. Kcal/lb & 1,502 & 1,498 & 1,493 & 1,488 & 1,507 & 1,502 & 1,497 & 1,493 & 1,511 & 1,506 & 1,501 & 1,496 \\
\hline SID Lys: ME ratio, g/mcal & 0.87 & 0.87 & 0.87 & 0.87 & 0.75 & 0.75 & 0.75 & 0.75 & 0.66 & 0.66 & 0.66 & 0.65 \\
\hline $\mathrm{CP}, \%$ & 18.6 & 18.5 & 18.5 & 18.4 & 16.7 & 16.7 & 16.6 & 16.5 & 15.6 & 15.6 & 15.5 & 15.4 \\
\hline Crude fat, $\%$ & 4.2 & 4.1 & 4.1 & 4.1 & 4.3 & 4.2 & 4.2 & 4.2 & 4.3 & 4.3 & 4.3 & 4.3 \\
\hline Crude fiber, \% & 3.6 & 3.6 & 3.6 & 3.5 & 3.5 & 3.5 & 3.5 & 3.4 & 3.5 & 3.5 & 3.4 & 3.4 \\
\hline $\mathrm{Ca}, \%$ & 0.59 & 0.60 & 0.60 & 0.61 & 0.53 & 0.53 & 0.54 & 0.54 & 0.45 & 0.46 & 0.46 & 0.47 \\
\hline $\mathrm{P}, \%$ & 0.40 & 0.40 & 0.41 & 0.42 & 0.37 & 0.38 & 0.39 & 0.40 & 0.36 & 0.37 & 0.38 & 0.39 \\
\hline Available P, \% & 0.14 & 0.15 & 0.16 & 0.17 & 0.14 & 0.15 & 0.16 & 0.17 & 0.13 & 0.14 & 0.15 & 0.17 \\
\hline Lactose, $\%$ & 0.0 & 0.9 & 1.9 & 2.8 & 0.0 & 0.9 & 1.9 & 2.8 & 0.0 & 0.9 & 1.9 & 2.8 \\
\hline
\end{tabular}

${ }^{1}$ Phase 1 diet was fed from d 0 to 19 ; phase 2 from d 19 to 36 , and phase 3 from d 36 to 53 . All diets were fed in pelleted form.

2, 3,4 Phases contain increasing amounts of SweetLac (SweetLac 63; Westway Feed Products, Tomball, TX).

5 VTM = vitamin and trace mineral premix, which provide per ton of premix: 8,000,000 IU vitamin A, 1,500,000 IU vitamin D, 40,000 IU vitamin E, 1,000 mg vitamin K, 30 $\mathrm{mg}$ B 12, 30,000 mg Niacin, 20,000 mg pantothenic acid, 5,000 mg riboflavin, $200 \mathrm{mg}$ biotin, 1,000 mg folic acid, 2,000 mg pyridoxine, $125 \mathrm{ppm} \mathrm{Zn,} 125 \mathrm{ppm}$ Fe, $22 \mathrm{ppm}$ $\mathrm{Mn}, 15 \mathrm{ppm} \mathrm{Cu}, 0.60 \mathrm{ppm} \mathrm{I}, 0.30 \mathrm{ppm}$ Se. Vitamin concentrations are expressed on a per lb of product basis; whereas mineral concentrations are expressed on a total percentage of premix basis

${ }^{6}$ RONOZYME HiPhos 2,700 provided 201 phytase units (FYT)/lb with a release of $0.11 \%, 0.10 \%$, and $0.09 \%$ of available P respectively for each phase. 
Table B3: Chemical Analysis of Experimental Diets (as-fed) ${ }^{1,2}$

\begin{tabular}{|c|c|c|c|c|c|c|c|c|c|c|c|c|}
\hline \multirow[b]{2}{*}{ Item, \% } & \multicolumn{4}{|c|}{ Phase 1} & \multicolumn{4}{|c|}{ Phase 2} & \multicolumn{4}{|c|}{ Phase 3} \\
\hline & Control & $2.5 \%^{3}$ & $5 \%^{4}$ & $7.5 \%^{5}$ & Control & $2.5 \%$ & $5 \%$ & $7.5 \%$ & Control & $2.5 \%$ & $5 \%$ & $7.5 \%$ \\
\hline Moisture & 11.40 & 11.70 & 11.93 & 12.23 & 10.23 & 10.97 & 11.33 & 11.17 & 10.90 & 11.37 & 11.77 & 12.07 \\
\hline Dry Matter & 88.60 & 88.30 & 88.07 & 87.77 & 89.77 & 89.03 & 88.67 & 88.83 & 89.10 & 88.63 & 88.23 & 87.97 \\
\hline Crude Protein & 17.60 & 18.19 & 18.67 & 19.10 & 16.76 & 16.65 & 17.63 & 17.42 & 15.15 & 15.07 & 15.35 & 15.45 \\
\hline Crude Fiber & 3.57 & 3.89 & 3.96 & 3.69 & 4.13 & 3.68 & 3.46 & 3.20 & 3.39 & 3.46 & 3.15 & 3.23 \\
\hline Ethanol Soluble CHO (Sugar) & 4.61 & 5.30 & 5.61 & 6.14 & 4.31 & 4.25 & 4.64 & 5.33 & 3.47 & 4.05 & 4.73 & 5.31 \\
\hline Crude Fat & 3.02 & 3.19 & 3.51 & 3.34 & 3.58 & 3.68 & 3.43 & 3.43 & 3.73 & 3.42 & 3.32 & 3.34 \\
\hline Ash & 4.47 & 4.46 & 5.02 & 5.29 & 4.28 & 4.14 & 4.60 & 4.79 & 3.50 & 3.79 & 3.77 & 3.80 \\
\hline Calcium & 0.66 & 0.64 & 0.74 & 0.65 & 0.62 & 0.50 & 0.49 & 0.57 & 0.42 & 0.38 & 0.36 & 0.40 \\
\hline Phosphorus & 0.44 & 0.46 & 0.48 & 0.49 & 0.41 & 0.41 & 0.42 & 0.44 & 0.40 & 0.41 & 0.42 & 0.42 \\
\hline Non Fiber Carbohydrates & 63.50 & 62.45 & 60.85 & 60.04 & 65.17 & 64.58 & 63.03 & 63.24 & 66.73 & 66.33 & 65.76 & 65.36 \\
\hline Non Structural Carbohydrates & 4.61 & 5.30 & 5.61 & 6.14 & 4.31 & 4.25 & 4.64 & 5.33 & 3.47 & 4.05 & 4.73 & 5.31 \\
\hline
\end{tabular}

${ }^{1}$ Samples were analyzed at Cumberland Valley Analytical Services (Hagerstown, MD).

${ }^{2}$ Liquid lactose product was obtained by Westway Feed Products (Tomball, TX).

3, 4,5 Phases contain increasing amounts of SweetLac (SweetLac 63; Westway Feed Products, Tomball, TX). 
Table B 4: Pellet Quality of Experimental Diets

\begin{tabular}{|c|c|c|c|c|c|c|c|}
\hline \multirow[b]{2}{*}{ It e $\mathrm{m}, \%$} & \multirow[b]{2}{*}{ Control } & \multirow[b]{2}{*}{$2.5 \%^{2}$} & \multirow[b]{2}{*}{$5 \%^{3}$} & \multirow[b]{2}{*}{$7.5 \%^{4}$} & \multirow[b]{2}{*}{ S E M } & \multicolumn{2}{|c|}{ Contrast $P-$ value $^{1}$} \\
\hline & & & & & & Line ar & Quadratic \\
\hline Fines ${ }^{5,6}$ & 3.96 & 2.57 & 3.22 & 1.83 & 1.481 & 0.251 & 0.997 \\
\hline $\mathrm{P} \mathrm{D} \mathrm{I}^{7}$ & 93.18 & 94.74 & 95.83 & 96.72 & 0.817 & 0.005 & 0.687 \\
\hline Hol men, $60 \mathrm{~s}^{8}$ & 85.65 & 89.96 & 91.94 & 92.40 & 1.357 & 0.002 & 0.173 \\
\hline $\mathrm{Holmen}, 120 \mathrm{~s}^{9}$ & 67.17 & 77.06 & 81.84 & 83.32 & 2.771 & 0.001 & 0.146 \\
\hline
\end{tabular}

${ }^{1}$ Results from experiment were considered significant at $P<0.05$ and a tendency between $P$ $>0.05$ and $P \leq 0.10$.

$2,3,4$ Phases contain increasing a mounts of SweetLac ( SweetLac 63; Westway Feed Products, To mball, TX).

${ }^{5}$ Percentage fines were determined using a number 6 screen $(3.35 \mathrm{~mm})$.

${ }^{6}$ Percentage Fines = (Weight of tumbled and sifted pellet (g)-Weight of sifted pellet (g))/ Weight of sifted pellet (g).

${ }^{7}$ P D I (pellet durability index) was determined by tumbling $500-\mathrm{g}$ samples of feed for 10 min and then using a number -6 screen $(3.35 \mathrm{~mm})$ to sift off the fines.

${ }^{8}$ Holmen NHP pellet durability tester (Tekpro Limited, Norfolk, United Kingdom) at 60 seconds.

${ }^{9}$ Holmen NHP pellet durability tester (Tekpro Limited, Norfolk, United Kingdom) at 120 seconds. 
Table B 5: Effects of increasing liquid lactose in finishing pig diets on growth performance ${ }^{1,2}$

\begin{tabular}{|c|c|c|c|c|c|c|c|}
\hline \multirow[b]{2}{*}{ It e m } & \multirow[b]{2}{*}{ Control } & \multirow[b]{2}{*}{$2.5 \%^{4}$} & \multirow[b]{2}{*}{$5 \%^{5}$} & \multirow[b]{2}{*}{$7.5 \%^{6}$} & \multirow[b]{2}{*}{ S E M } & \multicolumn{2}{|c|}{ Contrast $P-$ value ${ }^{3}$} \\
\hline & & & & & & Line ar & Quadratic \\
\hline \multicolumn{8}{|l|}{$\mathrm{B} \mathrm{W}, \mathrm{kg}$} \\
\hline d 0 & 53.9 & 53.8 & 53.9 & 54.2 & 1.04 & 0.831 & 0.817 \\
\hline d 53 & 120.0 & 118.5 & 120.0 & 118.7 & 2.031 & 0.697 & 0.958 \\
\hline \multicolumn{8}{|l|}{ d 0 to 53} \\
\hline A D G, $\mathrm{kg}$ & 1.21 & 1.22 & 1.23 & 1.21 & 0.029 & 0.852 & 0.517 \\
\hline A D F I, $\mathrm{kg}$ & 3.31 & 3.18 & 3.26 & 3.27 & 0.104 & 0.694 & 0.231 \\
\hline $\mathrm{G}: \mathrm{F}$ & 0.367 & 0.385 & 0.379 & 0.372 & 0.011 & 0.791 & 0.070 \\
\hline
\end{tabular}

${ }^{1}$ A total of 289 finishing pigs (DNA $241 \times 600$; initially $54 \mathrm{~kg}$ ) were used with 6 replicate pens per treatment and 8 to 14 pigs per pen. Research was conducted at Texas A \& M University, O.D. Butler Animal Science Teaching and Research Center, Nutrition and Physiology Center (College Station, $\mathrm{T} X)$.

${ }^{2}$ Three phases of experimental diets were fed from d 0 to 19 , d 19 to 36 and d 36 to 53 for Phases 1 , 2 and 3 , respectively.

${ }^{3}$ Results from experiment were considered significant at $\mathrm{P}<0.05$ and a tendency between $P>0.05$ and $P \leq 0.10$

4, 5, 6 Phases contain increasing a mounts of liquid lactose ( $S$ weetLac 63; Westway Feed Products,

To mball, TX). 
Table B 6: Carcass composition characteristics of pigs fed liquid lactose ${ }^{1}$

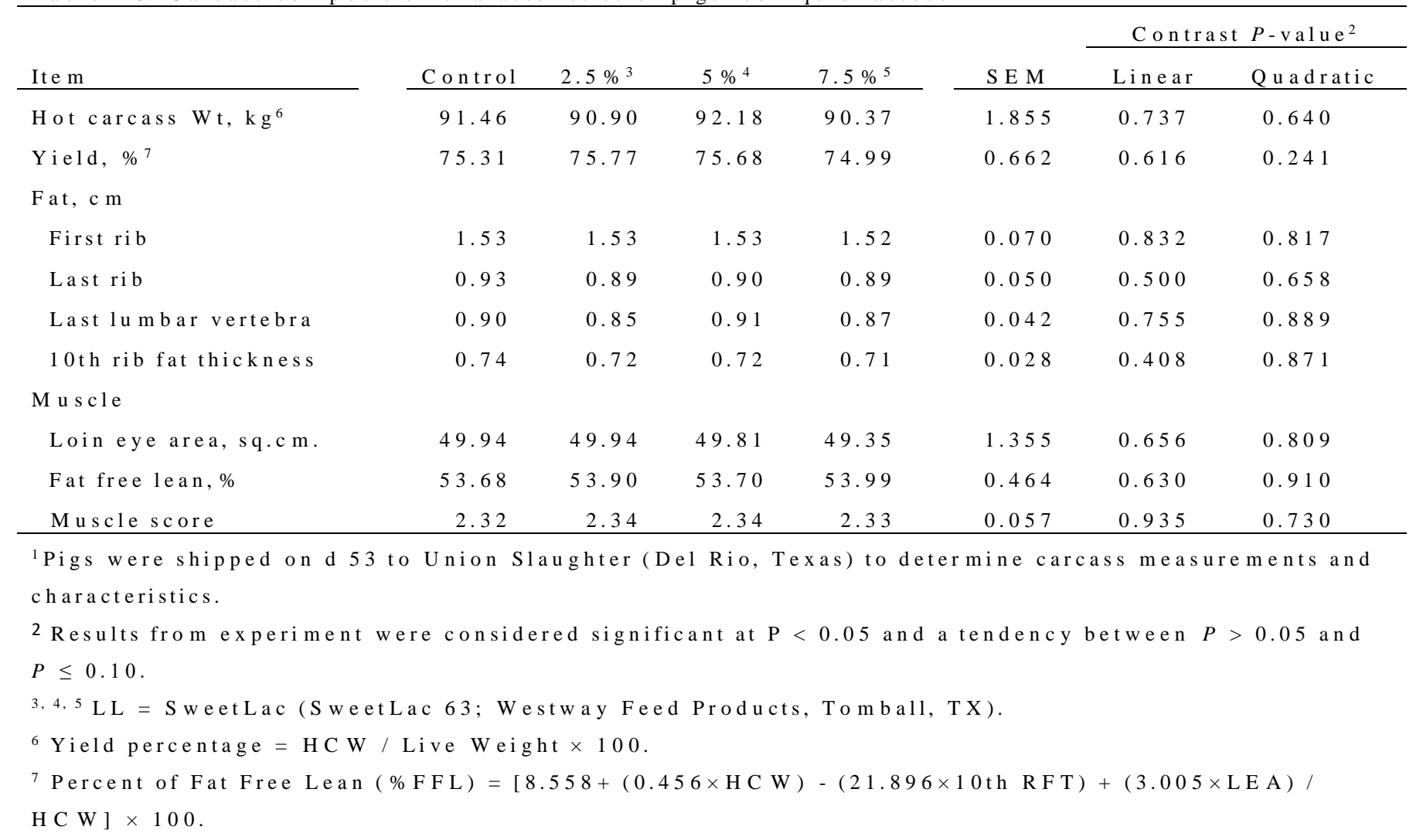

